\title{
IgE stimulates human and mouse arterial cell apoptosis and cytokine expression and promotes atherogenesis in $\mathrm{Apoe}^{-/-}$mice
}

\author{
Jing Wang, ${ }^{1}$ Xiang Cheng, ${ }^{1,2}$ Mei-Xiang Xiang, ${ }^{3}$ Mervi Alanne-Kinnunen, ${ }^{4}$ Jian-An Wang, ${ }^{3}$ \\ Han Chen, ${ }^{1,3}$ Aina He, ${ }^{1}$ Xinghui Sun, ${ }^{1}$ Yan Lin, ${ }^{3}$ Ting-Ting Tang, ${ }^{2}$ Xin Tu, ${ }^{5}$ Sara Sjöberg, ${ }^{1}$ \\ Galina K. Sukhova, ${ }^{1}$ Yu-Hua Liao, ${ }^{2}$ Daniel H. Conrad, ${ }^{6}$ Lunyin Yu, ${ }^{7}$ Toshiaki Kawakami, ${ }^{8}$ \\ Petri T. Kovanen, ${ }^{4}$ Peter Libby, ${ }^{1}$ and Guo-Ping Shi ${ }^{1}$
}

\begin{abstract}
1Department of Medicine, Brigham and Women's Hospital and Harvard Medical School, Boston, Massachusetts, USA. 2Institute of Cardiology, Union Hospital, Tongji Medical College, Huazhong University of Science and Technology, Wuhan, China. ${ }^{3}$ Department of Cardiology, the Second Affiliated Hospital, College of Medicine, Zhejiang University, Hangzhou, China. ${ }^{4}$ Wihuri Research Institute, Helsinki, Finland. ${ }^{5}$ College of Life Science and Technology and Center for Human Genome Research, Huazhong University of Science and Technology, Wuhan, China. ${ }^{6}$ Department of Microbiology and Immunology, Virginia Commonwealth University, Richmond, Virginia, USA. ${ }^{7}$ Department of Medicine, Massachusetts General Hospital and Harvard Medical School, Boston, Massachusetts, USA. ${ }^{8}$ Division of Cell Biology, La Jolla Institute for Allergy and Immunology, La Jolla, California, USA.
\end{abstract}

\begin{abstract}
IgE has a key role in the pathogenesis of allergic responses through its ability to activate mast cells via the receptor $F c \varepsilon R 1$. In addition to mast cells, many cell types implicated in atherogenesis express Fce R1, but whether IgE has a role in this disease has not been determined. Here, we demonstrate that serum IgE levels are elevated in patients with myocardial infarction or unstable angina pectoris. We found that IgE and the FceR1 subunit FcER1 $\alpha$ were present in human atherosclerotic lesions and that they localized particularly to macrophagerich areas. In mice, absence of Fc $\varepsilon \mathrm{R} 1 \alpha$ reduced inflammation and apoptosis in atherosclerotic plaques and reduced the burden of disease. In cultured macrophages, the presence of TLR4 was required for Fc\&R1 activity. IgE stimulated the interaction between $F c \varepsilon R 1$ and TLR4, thereby inducing macrophage signal transduction, inflammatory molecule expression, and apoptosis. These IgE activities were reduced in the absence of Fc $\varepsilon$ R1 or TLR4. Furthermore, IgE activated macrophages by enhancing $\mathrm{Na}^{+} / \mathrm{H}^{+}$exchanger 1 (NHE1) activity. Inactivation of NHE1 blocked IgE-induced macrophage production of inflammatory molecules and apoptosis. Cultured human aortic SMCs (HuSMCs) and ECs also exhibited IgE-induced signal transduction, cytokine expression, and apoptosis. In human atherosclerotic lesions, SMCs and ECs colocalized with IgE and TUNEL staining. This study reveals what we believe to be several previously unrecognized IgE activities that affect arterial cell biology and likely other IgE-associated pathologies in human diseases.
\end{abstract}

\section{Introduction}

IgE is an important regulator of allergic reactions, in which it activates mast cells (MCs) by binding to its high-affinity receptor FceR1 (1). In addition to allergic responses (2), MCs participate in other inflammatory diseases, including atherosclerosis $(3,4)$. IgE is the least abundant antibody isotype in humans, and its role in human immunology (other than its effects on allergy and parasitic infection) long has been unclear. In addition to MCs, dendritic cells, eosinophils, platelets, monocytes, and macrophages also bear FceR1 on their surfaces (5-9), albeit in different assemblages. For example, FceR1 on MCs is a heterotetramer $\left(\alpha \beta \gamma_{2}\right)$, whereas FceR1 on macrophages or eosinophils is a heterotrimer $\left(\alpha \gamma_{2}\right)(7)$. In dendritic cells, the expression of FceR1 affects IFN- $\gamma$-mediated proinflammatory (TNF- $\alpha$ ) and antiinflammatory (IL-10) cytokine production (6), as well as the efficiency of antigen uptake and presentation (10). Therefore, IgE's targets likely extend beyond MCs.

Macrophages are an important cell type in atherosclerotic lesions, the formation of macrophage foam cells being the hallmark of atherogenesis. Uptake of oxidized LDL (ox-LDL) particles by macro-

Authorship note: Jing Wang, Xiang Cheng, and Mei-Xiang Xiang contributed equally to this work.

Conflict of interest: The authors have declared that no conflict of interest exists. Citation for this article: J Clin Invest. 2011;121(9):3564-3577. doi:10.1172/JCI46028 phages, mediated primarily by cell-surface scavenger receptors (SRs), is an important pathway of foam cell formation. Interruption of this pathway in cell culture and in animal models blocks foam cell formation, thereby reducing atherogenesis $(11,12)$. But alternative pathways of lipid uptake have also been proposed. Atherosclerosisprone apoE-deficient $\left(\mathrm{Apoe}^{-/-}\right)$mice missing either CD36 or SR-A develop abundant macrophage foam cells in aortic sinus lesions (13). Indeed, macrophage SRs also play atheroprotective roles in both early and late phases of atherogenesis. Expression of decoy SRs retards early atherosclerotic lesion formation in experimental models (12). In advanced lesions, SR-associated signaling contributes to macrophage death and necrotic core formation (14), but this pro-atherogenic role of SRs is balanced by their ability to recognize and clear apoptotic cells in a nonphlogistic manner. Ox-LDL also has many signaling functions on macrophages that are mediated by TLRs - mainly by TLR2 and TLR4. Atherosclerosis-prone Apoe-/ mice or LDL receptor-knockout ( $\left(\mathrm{dll} /{ }^{\prime-}\right)$ mice lacking TLR2 or TLR4 demonstrate an impaired inflammatory response to hyperlipidemia and thus are resistant to atherosclerosis $(15,16)$.

In this study, we demonstrated that circulating IgE levels in patients with atherosclerosis associate with plaque instability. Furthermore, we found that IgE is present in atherosclerotic plaques and colocalizes with lesion macrophages, SMCs, and ECs. We demonstrated that IgE activates $\mathrm{Na}^{+} / \mathrm{H}^{+}$exchanger NHE1, which is followed by lowering 


\section{Table 1}

Clinical data and serum IgE comparison between patients with and without CHD from Central China

\begin{tabular}{lccc}
\hline & & & \\
Variables & Non-CHD $(\boldsymbol{n}=\mathbf{2 7 3})$ & CHD $(\boldsymbol{n}=\mathbf{7 0 9})$ & $\boldsymbol{P}$ \\
Age $(\mathrm{yr})$ & $56.48 \pm 0.71$ & $60.84 \pm 0.37$ & $0.000^{\mathrm{A}}$ \\
BMI $\left(\mathrm{kg} / \mathrm{mm}^{2}\right)$ & $23.43 \pm 0.16$ & $23.75 \pm 0.08$ & $0.050^{\mathrm{A}}$ \\
Fasting glucose $(\mathrm{mg} / \mathrm{dl})$ & $93.51 \pm 1.13$ & $96.98 \pm 0.86$ & $0.197^{\mathrm{A}}$ \\
TC $(\mathrm{mg} / \mathrm{dl})$ & $182.84 \pm 1.66$ & $195.86 \pm 1.04$ & $0.000^{\mathrm{A}}$ \\
TG $(\mathrm{mg} / \mathrm{dl})$ & $144.10 \pm 5.35$ & $137.87 \pm 2.44$ & $0.401^{\mathrm{A}}$ \\
HDL $(\mathrm{mg} / \mathrm{dl})$ & $49.29 \pm 0.74$ & $47.28 \pm 0.41$ & $0.044^{\mathrm{A}}$ \\
LDL (mg/dl) & $102.58 \pm 1.38$ & $115.28 \pm 0.90$ & $0.000^{\mathrm{A}}$ \\
IgE (IU/ml) & $57.13 \pm 5.35$ & $90.61 \pm 2.91$ & $0.000^{\mathrm{A}}$ \\
Sex (male, \%) & 47.99 & 52.19 & $0.238^{\mathrm{B}}$ \\
Smoking (\%) & 28.94 & 35.68 & $0.045^{\mathrm{B}}$ \\
Hypertension (\%) & 15.02 & 64.74 & $0.000^{\mathrm{B}}$ \\
Diabetes mellitus (\%) & 10.62 & 16.78 & $0.016^{\mathrm{B}}$ \\
& & &
\end{tabular}

Data are presented as mean \pm SEM or a percentage. AMann-Whitney $U$ test. BPearson's $\chi^{2}$ test.

of extracellular $\mathrm{pH}$, thereby promoting macrophage and vascular cell inflammation and apoptosis. IgE activities require cooperative interaction between FceR1 and TLR4 - two receptors present on several cell types relevant to the development of atherosclerosis.

\section{Results}

Enhanced serum IgE levels in patients with unstable plaques. In this study, we demonstrated that human serum IgE levels correlated with the degree of coronary heart disease (CHD) in two Chinese populations. Serum IgE levels were significantly higher in 709 patients with CHD than in 273 subjects without CHD $(90.61 \pm 2.91$ vs. $57.13 \pm 5.35 \mathrm{IU} / \mathrm{ml}, P<0.001$ ) from Central China (Table 1). After classifying CHD patients into acute myocardial infarction (AMI), unstable angina pectoris (UAP), and stable angina pectoris (SAP) groups, we found that AMI patients $(n=207,126.08 \pm 6.37$ $\mathrm{IU} / \mathrm{ml}$ ) had the highest serum IgE levels, followed by UAP patients $(n=255,89.60 \pm 4.89 \mathrm{IU} / \mathrm{ml})$ and SAP patients $(n=247,61.91 \pm 2.93$ $\mathrm{IU} / \mathrm{ml}$ ) (Table 2). Pearson's correlation test and independent sample $t$ test suggested that serum IgE correlated with smoking status
$(P=0.049)$, but not with age, sex, BMI, hypertension, diabetes mellitus, or serum lipid profiles (Table 3). Significantly increased serum IgE levels in patients with unstable atherosclerosis supported the hypothesis that IgE participates in human atherogenesis. To replicate these observations, we obtained an independent group of subjects with CHD $(n=147)$ and without CHD $(n=93)$ from Eastern China, and found results similar to those in the patient groups from Central China (Supplemental Tables 1 and 2; supplemental material available online with this article; doi:10.1172/JCI46028DS1). Serum IgE levels were significantly higher in CHD patients than in those without CHD (99.55 \pm 9.84 vs. $62.21 \pm 5.69 \mathrm{IU} / \mathrm{ml}$, $P=0.001)$. Pearson's correlation test and independent sample $t$ test suggested that serum IgE correlated with fasting glucose $(P=0.001)$, but not with smoking or other variables (Supplemental Table 3). AMI patients $(n=33,133.63 \pm 26.28 \mathrm{IU} / \mathrm{ml}) \mathrm{had}$ the highest serum IgE levels, followed by UAP patients $(n=83$, $97.72 \pm 12.41 \mathrm{IU} / \mathrm{ml})$ and SAP patients $(n=31,68.18 \pm 15.76$ $\mathrm{IU} / \mathrm{ml}$ ) (Supplemental Table 2).

Increased local IgE and FceR1 levels in buman atherosclerotic plaques. To examine further $\operatorname{IgE}$ involvement in atherosclerosis, we immunostained parallel frozen sections of human atherosclerotic lesions for IgE, its high-affinity receptor FceR1 $\alpha$ (1), and cell type-specific antibodies for macrophages (CD68), SMCs $(\alpha$-actin), and ECs (CD31) (17). Enhanced atherosclerotic lesion IgE and FceR1 $\alpha$ immunoreactivities localized to $\mathrm{CD}^{+} 8^{+}$macrophage-rich shoulder and adventitia regions, $\alpha$-actin-positive SMC-rich fibrous caps, and CD $31^{+}$ECs in the luminal surface (Figure 1, A-C), all of which outnumbered MCs in human and mouse atherosclerotic lesions $(4,18)$. Using immunoblot analysis, we confirmed FceR1 $\alpha$ expression in these cells. When $20 \mu \mathrm{g}$ of cell lysates was used, FceR1 $\alpha$ expression was clearly visible in human monocyte-derived macrophages, but hardly visible in human aortic SMCs (HuSMCs) or ECs (Figure 1D). Overexposure of the immunoblot film revealed expression of FceR1 $\alpha$ in SMCs and ECs after stimulation with the inflammatory cytokine IFN- $\gamma$, which operates in human atherosclerotic lesions (ref. 19 and data not shown). To enhance the FceR $1 \alpha$ signals from SMCs and ECs, we used $50 \mu \mathrm{g}$ cell lysates from these cells, while $2 \mu \mathrm{g}$ cell lysates from macrophages was sufficient. Under these loading conditions (Fig-

\section{Table 2}

Clinical data and serum IgE comparison among CHD subgroups and non-CHD subjects from Central China

Variables
Age $(\mathrm{yr})$
BMl $\left(\mathrm{kg} / \mathrm{mm}^{2}\right)$
Fasting glucose $(\mathrm{mg} / \mathrm{dl})$
TC $(\mathrm{mg} / \mathrm{dl})$
TG $(\mathrm{mg} / \mathrm{dl})$
HDL $(\mathrm{mg} / \mathrm{dl})$
LDL $(\mathrm{mg} / \mathrm{dl})$
IgE $(\mathrm{IU} / \mathrm{ml})$
Sex (male, \%)
Smoking $(\%)$
Hypertension (\%)
Diabetes mellitus (\%)

Non-CHD $(\boldsymbol{n}=\mathbf{2 7 3})$
$56.48 \pm 0.71$
$23.43 \pm 0.16$
$93.51 \pm 1.13$
$182.84 \pm 1.66$
$144.10 \pm 5.35$
$49.29 \pm 0.74$
$102.58 \pm 1.38$
$57.13 \pm 5.35$
47.99
28.94
15.02
10.62

AMI $(\boldsymbol{n}=\mathbf{2 0 7})$
$61.87 \pm 0.70^{\mathrm{A}}$
$23.88 \pm 0.16^{\mathrm{E}}$
$95.22 \pm 1.50$
$194.98 \pm 1.89^{\mathrm{A}}$
$129.36 \pm 3.37$
$45.86 \pm 0.75^{\mathrm{A}}$
$109.16 \pm 1.55^{\mathrm{A}}$
$126.08 \pm 6.37^{\mathrm{A}}$
57.49
30.43
$58.45^{\mathrm{A}}$
14.00

UAP $(\boldsymbol{n}=\mathbf{2 5 5})$
$61.69 \pm 0.66^{\mathrm{A}, \mathrm{B}}$
$23.64 \pm 0.14$
$99.38 \pm 1.61$
$202.11 \pm 1.64^{\mathrm{A}, \mathrm{F}, \mathrm{G}}$
$141.44 \pm 4.50$
$48.89 \pm 0.64^{\mathrm{F}}$
$120.79 \pm 1.46^{\mathrm{A}, \mathrm{F}, \mathrm{G}}$
$89.60 \pm 4.89^{\mathrm{A}, \mathrm{F}, \mathrm{G}}$
50.20
$47.06^{\mathrm{A}, \mathrm{F}, \mathrm{G}}$
$70.20^{\mathrm{A}, \mathrm{C}}$
$21.57^{\mathrm{B}, \mathrm{C}, \mathrm{E}}$

$\begin{array}{cc}\operatorname{SAP}(\boldsymbol{n}=\mathbf{2 4 7}) & \boldsymbol{P} \\ 59.03 \pm 0.57^{\mathrm{A}, \mathrm{C}} & 0.000^{\mathrm{D}} \\ 23.76 \pm 0.15 & 0.194^{\mathrm{D}} \\ 95.98 \pm 1.32 & 0.402^{\mathrm{D}} \\ 189.21 \pm 1.76^{\mathrm{C}, \mathrm{E}} & 0.000^{\mathrm{D}} \\ 143.61 \pm 4.77 & 0.052^{\mathrm{D}} \\ 47.04 \pm 0.75^{\mathrm{E}} & 0.001^{\mathrm{D}} \\ 114.70 \pm 1.57^{\mathrm{A}, \mathrm{C}} & 0.00^{\mathrm{D}} \\ 61.91 \pm 2.93 & 0.000^{\mathrm{D}} \\ 49.80 & 0.196^{\mathrm{H}} \\ 28.34 & 0.000^{\mathrm{H}} \\ 64.37^{\mathrm{A}} & 0.000^{\mathrm{H}} \\ 14.17 & 0.005^{\mathrm{H}}\end{array}$




\section{Table 3}

Variables associated with serum $\lg \mathrm{E}$ in all subjects $(n=982)$

\begin{tabular}{lccc} 
Variables & $\boldsymbol{r}$ & $\boldsymbol{t}^{\mathbf{A}}$ & $\boldsymbol{P}^{\mathbf{B}}$ \\
Age $(\mathrm{yr})$ & 0.053 & & 0.243 \\
Sex & 0.131 & 0.094 & \\
BMl $\left(\mathrm{kg} / \mathrm{mm}^{2}\right)$ & 0.042 & & 0.188 \\
Hypertension & 0.052 & 0.106 & \\
Smoking & 0.063 & 0.049 & \\
Diabetes mellitus & 0.096 & 0.730 & \\
Fasting glucose (mg/dl) & -0.023 & & 0.476 \\
TC (mg/dl) & 0.019 & & 0.557 \\
TG (mg/dl) & 0.051 & & 0.133 \\
HDL (mg/dl) & -0.020 & & 0.538 \\
LDL (mg/dl) & 0.012 & & 0.700 \\
& & & \\
\hline
\end{tabular}

AIndependent sample $t$ test. BPearson's correlation test.

ure 1D), we detected increased FceR1 $\alpha$ expression in IFN- $\gamma$-treated SMCs (lanes 2 and 3) and ECs (lanes 5 and 6). Together, these data showed that the expression of FceR $1 \alpha$ is high and constitutive in cultured macrophages, and it is low and inducible in cultured arterial SMCs and ECs. These results in cultured cells agree with those from the immunohistochemistry analysis (Figure $1, A-C$ ). The majority of macrophage-rich areas contained FceR1 $\alpha$, whereas only a small portion of SMC-rich areas and ECs in the lumen contained IgE and FceR1 $\alpha$.

Reduced atherosclerosis in FceR1 $\alpha$-deficient mice. As in CHD patients, serum IgE levels increased significantly in $A p o e^{-/-}$mice after consumption of a high-fat diet (Western diet) (Figure 2A). To test a direct role of IgE in atherogenesis, we crossed FceR1 $\alpha$-deficient mice $\left(\right.$ Fcerla $\left.^{-/-}\right)(20)$ with atherosclerosis-prone Apoe $e^{-/-}$mice. After 12 weeks on a Western diet, Apoe $e^{-/-}$mice that were WT for FceR1 $\alpha$

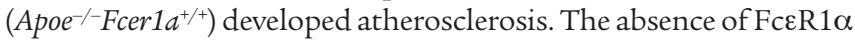
$\left(\right.$ Apoe $\left.{ }^{-/-} \mathrm{Fcerla}^{-/-}\right)$significantly reduced aortic lipid deposition and aortic arch intima areas (Figure 2, B and C), although media areas were not affected (Figure 2D). Atherosclerotic lesion characterizations demonstrated that lesion contents of macrophages, $\mathrm{T}$ cells, and the inflammatory cytokine IL-6, as well as MHC class II molecule levels (Figure 2E), were significantly reduced in $\mathrm{Apoe}^{-/-}$ $\mathrm{Fcerla}^{-/-}$mice, suggesting attenuated inflammation in the absence of FcER1 $\alpha$. In addition to reduced inflammation, Apoe $e^{-/-} \mathrm{Fcer}_{1 a^{-/-}}$ mice showed significantly reduced apoptosis of lesional cells (Figure $2 \mathrm{~F}$ ). In early lesions, macrophage apoptosis limits lesion cellularity and suppresses lesion progression. In advanced lesions, however, macrophage apoptosis promotes the development of the necrotic core - a key factor of plaque vulnerability and acute luminal thrombosis - and associates with plaque necrosis (21). The number of necrotic cores (Figure $2 \mathrm{G}$ ) as well as necrotic core areas from both aortic arches $\left(0.016 \pm 0.005 \mathrm{~mm}^{2} \mathrm{vs} .0 .065 \pm 0.016\right.$ $\left.\mathrm{mm}^{2}, P=0.021\right)$ and brachiocephalic arteries $\left(0.025 \pm 0.004 \mathrm{~mm}^{2}\right.$ vs. $\left.0.071 \pm 0.019 \mathrm{~mm}^{2}, P=0.044\right)$ were significantly smaller in Apoe ${ }^{-/-} \mathrm{Fcerla}^{-/-}$mice than in Apoe $e^{-/-} \mathrm{Fcerla}^{+/+}$mice.

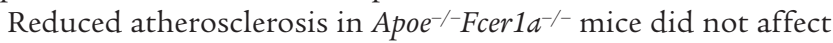
serum total cholesterol (TC) or LDL levels, but increased serum triglyceride (TG) and HDL levels (Supplemental Table 4). Although TG levels did not reach statistical significance $(P=0.08)$, HDL levels were significantly higher in $A$ poe $^{-/-} \mathrm{Fcer}_{1 \mathrm{a}^{-/-}}$mice than in Apoe $e^{-/-}$Fer $1 a^{+/+}$mice $(P=0.019)$. Serum fast performance liquid

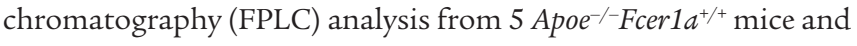

5 Apoe $^{-/-} \mathrm{Fcer}_{1 \mathrm{a}^{-/-}}$mice demonstrated similar lipid profiles. Both $\operatorname{VLDL}(P=0.015)$ and HDL $(P=0.01)$ absorbance units were significantly higher in serum from Apoe $e^{-1-} \mathrm{Fcer}_{1 a^{-/-}}$mice than in serum from Apoe ${ }^{-/-} \mathrm{Fcer}_{\mathrm{A} \mathrm{a}^{+/+}}$mice, but LDL absorbance units in the two groups of mice were comparable (Supplemental Figure 1).

IgE activities require interactions of FcER 1 and TLR4. Abundant FceR1 $\alpha$ expression in macrophages (Figure 1, A and D) suggests that IgE function in atherosclerosis reaches beyond MC activation. Exposure to purified IgE from a mouse hybridoma (SPE-7) (22) elicited dose-dependent and time-dependent cell signaling molecule activation in mouse peritoneal macrophages - including the stress and inflammation signals JNK and MAPK (p38) and cell proliferation signal ERK (Figure 3, A and B). After 15 minutes of $50 \mu \mathrm{g} / \mathrm{ml}$ IgE treatment, macrophages from WT mice, but not those from $\mathrm{Fcerla}^{-/-}$mice, showed increased phosphorylation of ERK1/2 and JNK (Figure 3C), suggesting that IgE stimulates macrophage signal transduction via FceR1. When macrophages from WT mice were stimulated with IgE for 2 days, activities of the proatherogenic cysteine proteases cathepsin $\mathrm{S}$ and cathepsin $\mathrm{K}(17,23)$ increased, as detected by cysteinyl cathepsin active site labeling (17), an action of IgE not displayed by macrophages from Fcerla ${ }^{-/}$mice (Figure 3D). To test whether IgE-mediated macrophage signaling and protease production were due to contamination of LPS, which remains active after boiling for 30 minutes (24), we heat inactivated mouse IgE for 5 minutes at boiling and found that heated $\operatorname{IgE}$ did not stimulate phosphorylation of JNK or p $65 \mathrm{NF}-\kappa \mathrm{B}$, arguing against the possibility that LPS contamination accounted for the effects attributed to mouse IgE. As a positive control, LPS alone activated macrophage p 65 NF- $\mathrm{KB}$, likely via TLR4 (Figure 3E and ref. 25). We also detected no LPS contamination (undetectable level) in our hybridoma-derived mouse IgE using the ToxinSensor Chromogenic LAL Endotoxin Assay Kit (GenScript). To evaluate further the possibility of LPS contamination accounting for the effects of mouse hybridoma-derived IgE, we stimulated macrophages from WT mice, Fcerla $a^{-/-}$mice, and $\mathrm{Tlr} 4^{-/-}$mice with $\mathrm{IgE}$ and found, surprisingly, that IgE had a negligible effect on p 65 and ERK phosphorylation in macrophages from both $\mathrm{Fcerla}^{-/-}$mice and $\mathrm{Tlr}^{-/-}$mice (Figure $3 \mathrm{~F})$. Consistent with these findings, $\operatorname{IgE}$ induced increases in both the mRNA (real-time PCR) and media protein levels (ELISA) of IL-6 and of the chemokine monocyte chemotactic protein-1 (MCP-1) in 2 days, as well as apoptosis (in situ immunofluorescence TUNEL staining) in 3 days, in macrophages from WT mice and Tlr2 ${ }^{-/-}$mice - but the same cells from Fcer $1 a^{-/-}$mice and Tlr $4^{-/-}$mice failed to respond to IgE (Figure 3, G-I). Because IgE did not contain LPS (Figure 3E), loss of IgE-induced cell signaling, cytokine and chemokine expression, and apoptosis in $\mathrm{Tlr}^{-/-}$and Fcerla $\mathrm{a}^{-/-}$macrophages suggested that IgE function requires both TLR4 and FceR1. Thus, we prepared cell lysates from WT macrophages that were pretreated with or without $50 \mu \mathrm{g} / \mathrm{ml} \operatorname{IgE}$ for 15 minutes, and then performed co-immunoprecipitation with anti-FceR $1 \alpha$ or TLR4 antibodies, followed by immunoblot analysis with antibodies to detect TLR 4 or FceR1 $\alpha$. IgE treatment did not increase total cellular TLR4, FceR1 $\alpha$, or $\beta$-actin protein levels (Figure 3J), but formed a complex between TLR 4 and FceR $1 \alpha$ as confirmed by co-immunoprecipitation for FceR $1 \alpha$ and then immunoblot for TLR4, or co-immunoprecipitation for TLR4 and immunoblot for FceR1 $\alpha$ (Figure 3K). The same co-immunoprecipitation antibodies were used for immunoblot analysis to confirm equal antibody precipitation between the samples. Therefore, FceR1 $\alpha$ and TLR 4 co-immunoprecipitated after IgE stimulation, which explains the 

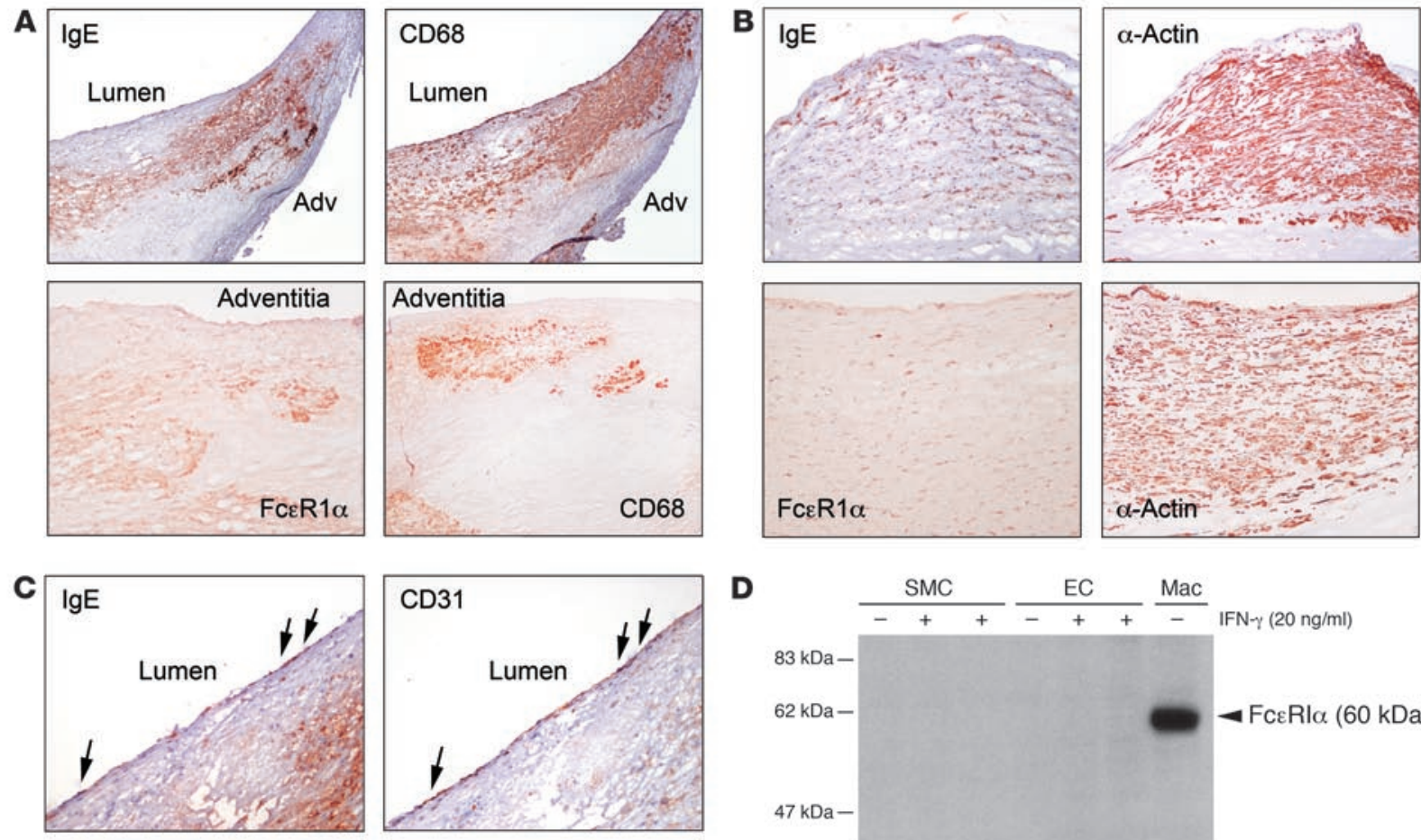

D

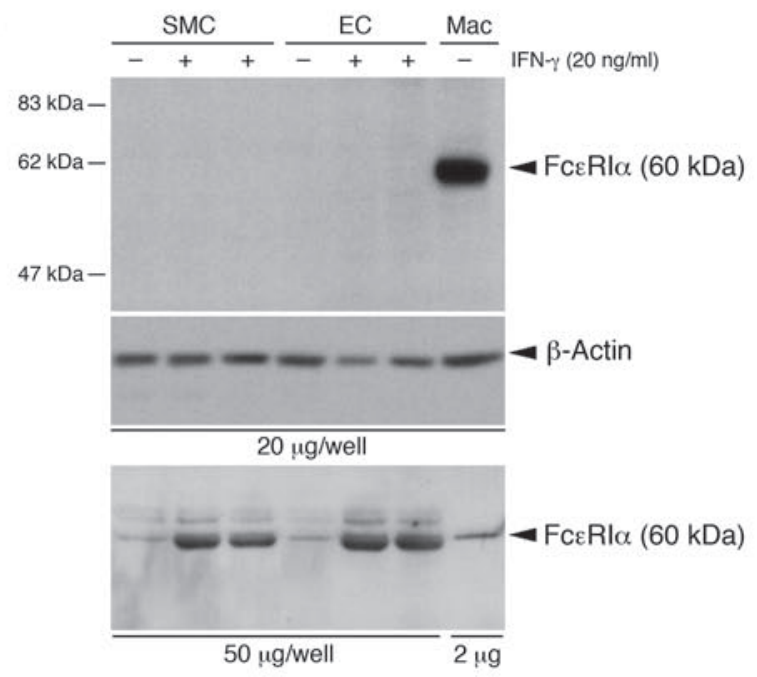

\section{Figure 1}

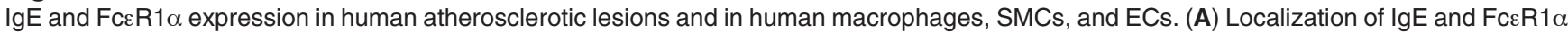
in $\mathrm{CD}_{68}{ }^{+}$macrophage-rich areas in human atherosclerotic lesions. Original magnification, top panels: $\times 40$, bottom panels: $\times 100$. Adv, adventitia. (B) Localization of IgE and FceR1 $\alpha$ in $\alpha$-actin-positive SMC-rich fibrous cap (top panels, $\times 100)$ and media (bottom panels, $\times 100)$. (C) Localization of $\operatorname{lgE}(\times 100)$ and $\mathrm{FCE}_{\mathrm{R} 1 \alpha}(\times 400)$ in luminal ECs $(\mathrm{CD} 31, \times 100)$ (arrows). Antibody isotype control was used as a negative control $(\times 100)$. (D) FceR1 $\alpha$ immunoblot analysis in human monocyte-derived macrophages (Mac) and in HuSMCs and HuECs treated without (-) and with (+) inflammatory cytokine IFN- $\gamma$. Each lane contains $20 \mu \mathrm{g}$ cell lysate (top panel). Actin immunoblot ensured equal protein loading. Bottom panel: $2 \mu \mathrm{g}$ of human macrophage lysate and $50 \mu \mathrm{g}$ of HuEC and HuSMC lysates to enhance the detection of FceR $1 \alpha$ in SMCs and ECs. IFN- $\gamma$ (20 $\mathrm{ng} / \mathrm{ml}$ ) induced FCعR1 $\alpha$ expression in SMCs (lanes 2 and 3) and ECs (lanes 5 and 6).

observation that deficiency of FceR1 $\alpha$ or TLR4 inhibited IgE-mediated macrophage signaling, inflammatory molecule expression, and apoptosis (Figure 3, F-I). The role of TLR4 in macrophage apoptosis in atherosclerotic lesions has been demonstrated in several studies. This pattern recognition receptor mediates SR-A-induced apoptosis in ER-stressed macrophages. Macrophages from $M y d 88^{-/-}$mice or lacking TLR4 are resistant to SR-A ligand fucoidan- and unfold protein response (UPR) activator thapsigargin-induced apoptosis (26). TLR2/TLR4 deficiency in bone marrow-derived cells suppresses atherosclerotic lesion macrophage apoptosis and plaque necrosis in $\mathrm{Ldlr}^{/-}$mice after 10 weeks of an atherogenic diet (27).

To examine whether IgE may use its low-affinity receptor FceR2 (CD23) to mediate macrophage biology, we stimulated peritoneal macrophages from $C d 23^{-/-}$mice (28) and demonstrated no significant differences in apoptosis and IL- 6 production compared with those from $\mathrm{Cd}_{23^{+/+}}$littermates (C57BL/6 background) (data not shown), suggesting that FceR1 is the dominant receptor for IgE.

IgE regulates NHE1 activities in macrophages. In human atherosclerotic lesions, areas with clusters of $\mathrm{CD}^{+} 8^{+}$macrophages that also contained high amounts of $\operatorname{IgE}$ and $\mathrm{Fc \varepsilon R} 1 \alpha$ were often highly positive for TUNEL staining (Figure 4A). In contrast, macrophagerich regions that contained low levels of IgE and FceR $1 \alpha$ had only a few apoptotic cells (Figure 4B), suggesting a role of IgE in human macrophage apoptosis. As in mouse macrophages (Figure 3I), immunoaffinity-purified human plasma $\operatorname{IgE}(50 \mu \mathrm{g} / \mathrm{ml})$ (Figure 4C) or mouse IgE (SPE-7, $50 \mu \mathrm{g} / \mathrm{ml}$ ) (Supplemental Figure 2) induced human macrophage apoptosis, which could be blocked with a caspase inhibitor, ZVAD-FMK $(20 \mu \mathrm{M})$, although there were some donor-to-donor variations among different human macrophage preparations. Surprisingly, we found that IgE induced mac- 
A

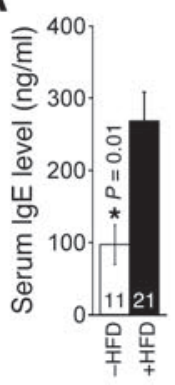

B

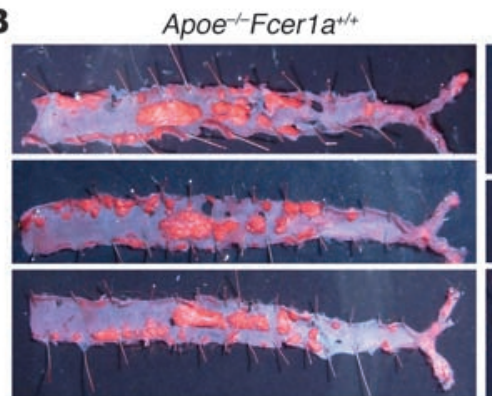

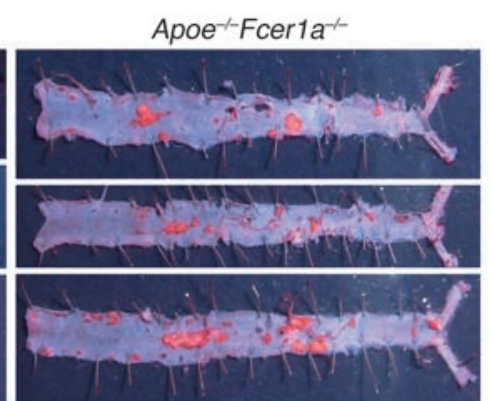

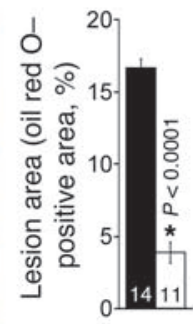

Apoe $^{-/-F c e r 1 a^{+/+}}$ Apoe $^{-/}$Fcer1a ${ }^{-1}$
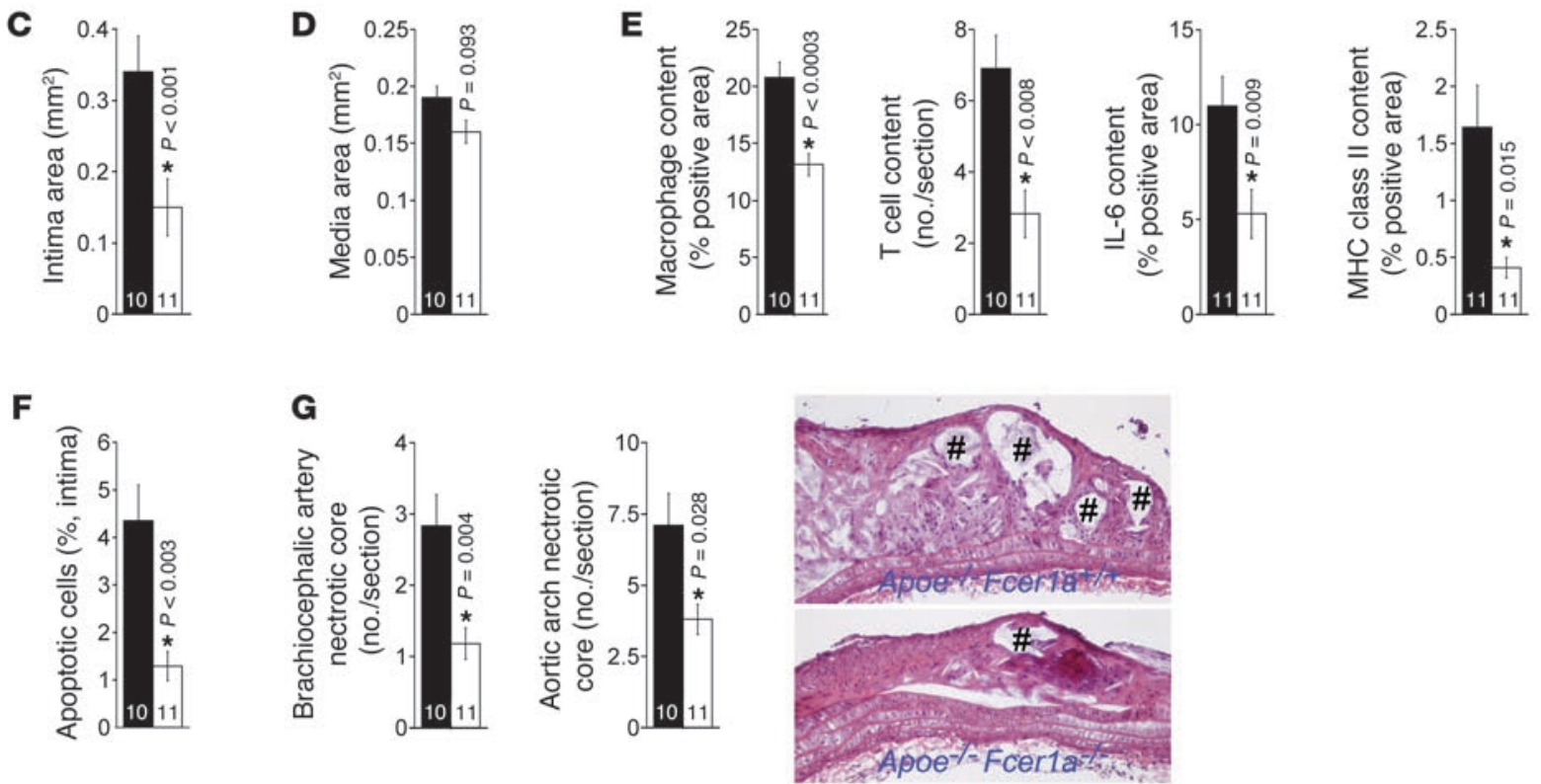

\section{Figure 2}

Deficiency of FceR1 $\alpha$ reduced atherogenesis in Apoe ${ }^{-/}$mice. (A) Serum IgE levels in Apoe ${ }^{-/}$mice before (-HFD) and after (+HFD) consumption of a high-fat diet for 12 weeks. (B) Thoracic-abdominal aorta lipid deposition (oil red O staining). Representative images are shown. (C) Intima area. (D) Media area. (E) Aortic arch atherosclerotic lesion macrophage content, CD3 ${ }^{+} \mathrm{T}$ cell content, IL-6-positive area, and MHC class II content. (F) Lesion TUNEL-positive apoptosis cells. (G) Brachiocephalic artery and aortic arch necrotic core (\#) numbers. Representative aortic arch necrotic cores are shown (original magnification, $\times 40$ ). The key in $\mathbf{B}$ applies to $\mathbf{B}-\mathbf{G}$. The number of mice per group is indicated in each bar. Data are mean \pm SEM. Asterisks indicate statistically significant differences; Mann-Whitney $U$ test.

rophage apoptosis by reducing extracellular $\mathrm{pH}$ with noticeable medium color change, and that this activity depended on NHE1 activity. NHE1 inhibition with $10 \mu \mathrm{M}$ ethylisopropylamiloride (EIPA) completely blocked the IgE-induced medium color change and $\mathrm{pH}$ reduction (Figure 4D), suggesting that reduced $\mathrm{pH}$ after IgE treatment was not caused by increased cell lysis or IgE contamination, but rather by enhanced NHE1 activity. EIPA treatment alone did not change $\mathrm{pH}$ (Figure 4D) or cause cell death. When 100 $\mathrm{ng} / \mathrm{ml}$ LPS induced human macrophage apoptosis by greater than $50 \%$ in approximately $2-3$ days, $10 \mu \mathrm{M}$ EIPA did not cause any cell death under the same condition (data not shown). Human macrophages underwent apoptosis within 3 days if they were cultured in acidic ( $\mathrm{pH}$ 6.5) DMEM, but were resistant to apoptosis in neutral ( $\mathrm{pH}$ 7.5) DMEM (Figure 4E). Our observations agree with previous findings that advanced human and rabbit atherosclerotic lesions become acidic compared with healthy arterial intima (29) and that macrophages augment uptake of modified lipid and foam cell formation in an acidic environment (30), although a $\mathrm{pH}$ effect on macrophage apoptosis has not been noted. In contrast to macrophages in human atherosclerotic plaques exposed to IgE (Figure 4A) and acidic $\mathrm{pH}$ (29), cultured human macrophages undergo apoptosis at acidic $\mathrm{pH}$, but $\mathrm{pH}$ changes $(\mathrm{pH} 7.5$ or $\mathrm{pH} 6.5$ ) without IgE did not affect MAPK (ERK1/2 and p38) or NF-KB (p65) phosphorylation (Supplemental Figure 3). When human macrophages underwent apoptosis and released IL- 6 to the media after IgE stimulation, EIPA significantly blocked cell death and IL- 6 secretion of macrophages from most donors (Figure 4, F and G).

As the effects of IgE on IL-6 production (Figure 4G) or apoptosis (Figure 4F and Supplemental Figure 1) in macrophages varied among donors, we tested and affirmed the IgE effects on macrophage $\mathrm{pH}$ changes and apoptosis in mouse peritoneal macrophages. As in human macrophages, IgE induced macrophage IL-6 production (Figure 5A) and apoptosis by activating NHE1 (Figure 5B). Pharmacological inhibition of NHE1 with approximately 50-100 $\mu \mathrm{M}$ NHE1 inhibitor EIPA blocked IgE-induced macrophage secretion of IL- 6 or apoptosis. Mechanistically, IgE induced 
A

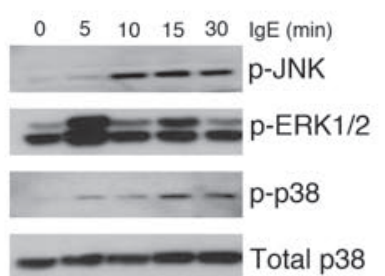

E

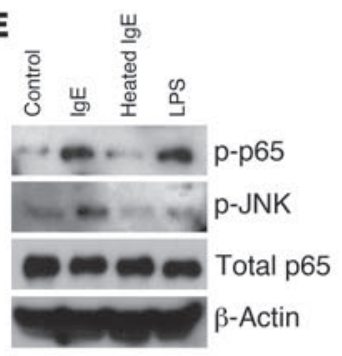

H

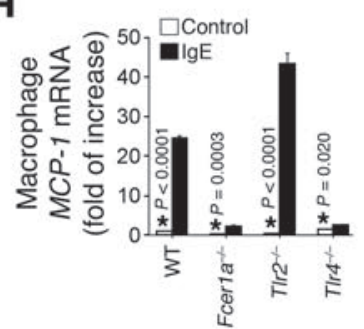

J

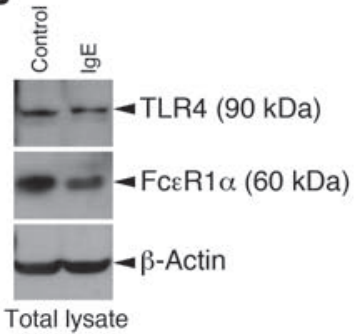

B

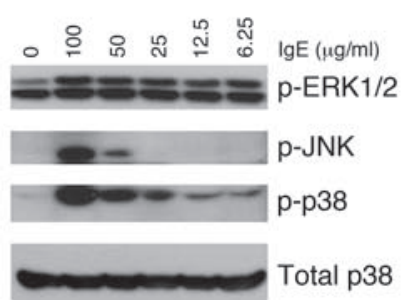

F

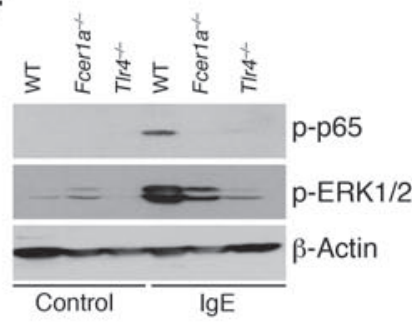

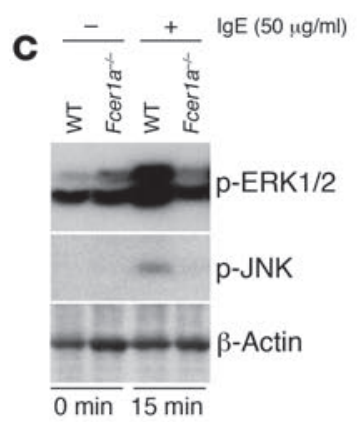

D

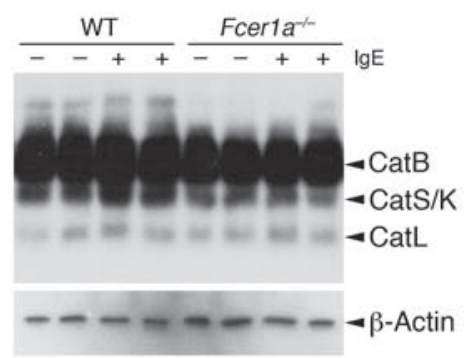

G
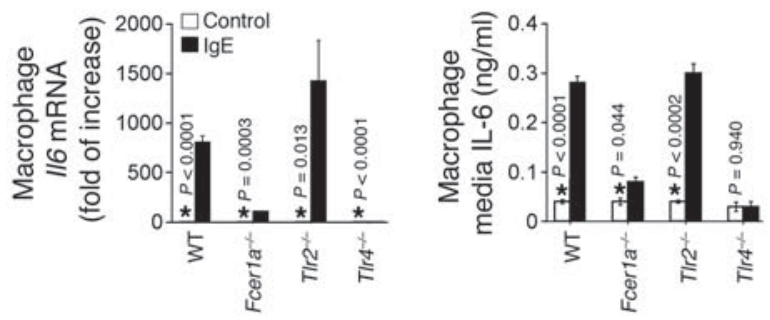

I
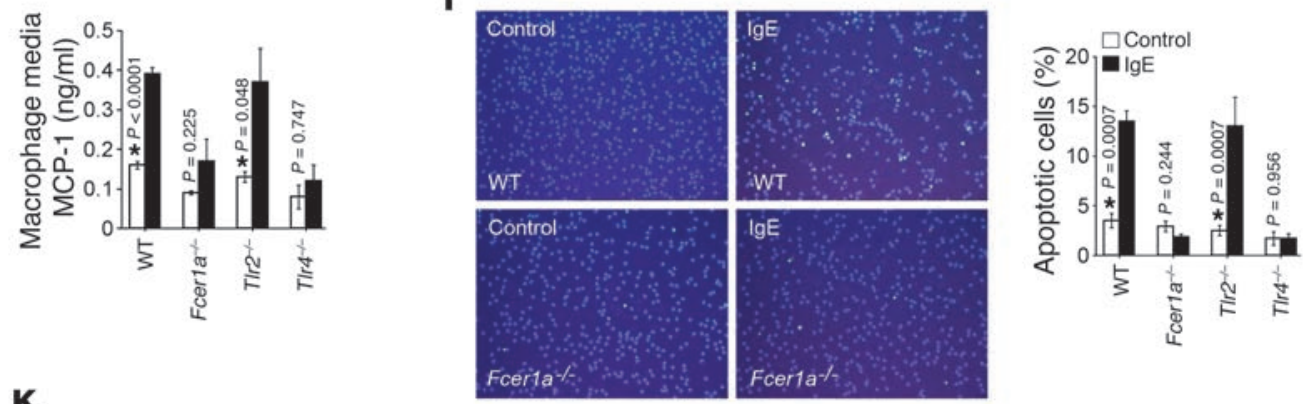

K
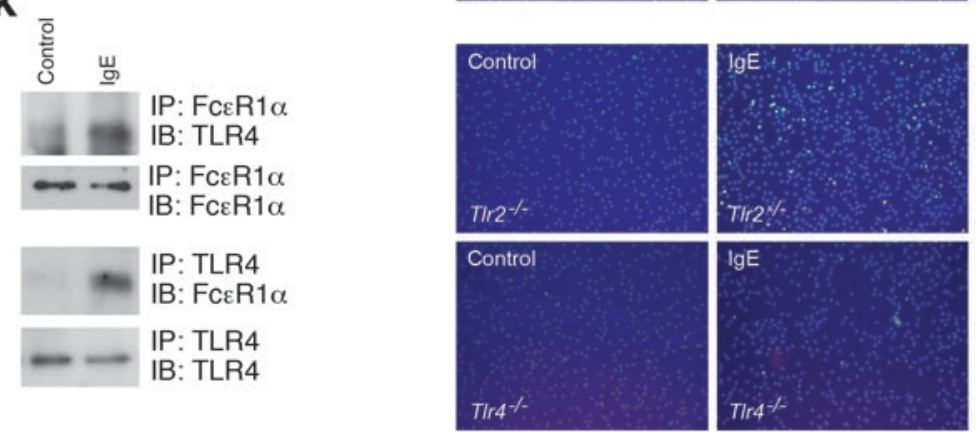

\section{Figure 3}

Mouse peritoneal macrophage IgE (SPE-7) responses. Immunoblots to detect signaling molecule activation in IgE-treated macrophages at different times (50 $\mu \mathrm{g} / \mathrm{ml} \mathrm{IgE})$ (A) or with different doses of IgE (15 minutes) (B). (C) Immunoblots to detect signaling molecule activation in IgE-treated macrophages from WT and Fcer1 $a^{-/-}$mice. (D) Macrophage lysate JPM labeling to detect active cathepsins (Cat; arrowheads) in macrophages treated without (-) or with (+) IgE for 2 days. (E) WT macrophage phospho-p65 and phospho-JNK expression after 15 minutes of treatment with IgE, heated IgE, and LPS (100 ng/ml). (F) IgE-stimulated phospho-p65 and phospho-JNK expression in macrophages from different mice. (G and $\mathbf{H}$ ) IgE-induced $/ / 6$ and MCP-1 mRNA (RT-PCR) and media protein (ELISA) levels in macrophages from different mice. (I) Immunofluorescence TUNEL staining of IgE-induced apoptosis (3 days) in macrophages from different mice. Left panels are representative images (original magnification, $\times 100$ ). (J) Immunoblots to detect TLR4 and FCER1 $\alpha$ in macrophage total lysates before and after IgE stimulation (15 minutes). (K) Immunoprecipitation for Fc\&R1 $\alpha$ or TLR4 followed by immunoblot analysis for TLR4 or Fc\&R1 $\alpha$ in macrophages treated with and without IgE (15 minutes). The same immunoprecipitation (IP) antibody was used for immunoblot (IB) to ensure equal antibody precipitation. Except where indicated, $50 \mu \mathrm{g} / \mathrm{ml}$ of $\mathrm{IgE}$ or heated $\mathrm{IgE}$ was used for all macrophage stimulations. Total p38, p65, or $\beta$-actin immunoblots were used for protein loading controls. Data in G-I are mean \pm SEM of 6-10 experiments. Asterisks indicate statistically significant differences; Mann-Whitney $U$ test. 
A

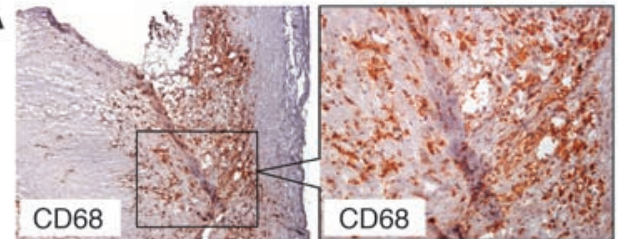

B
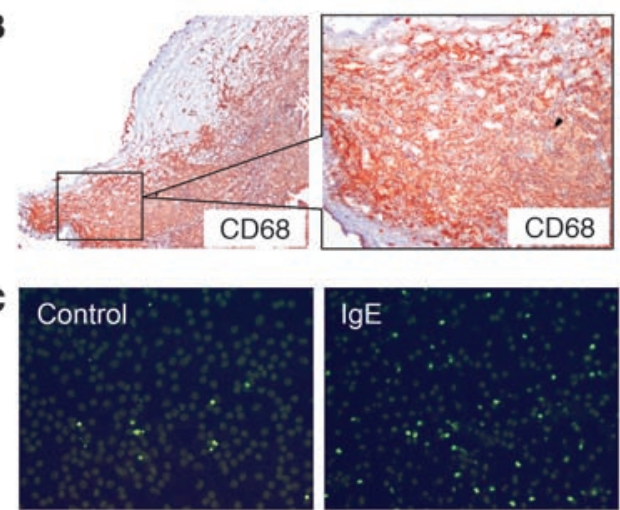
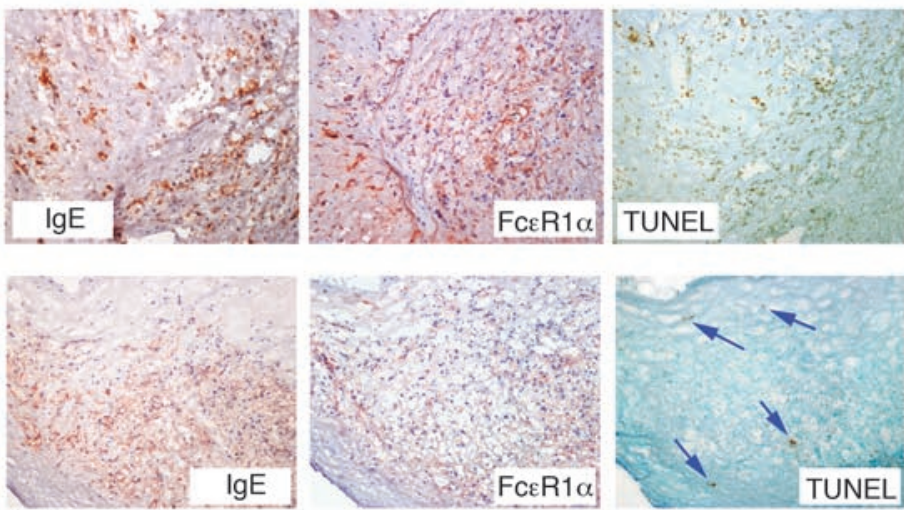
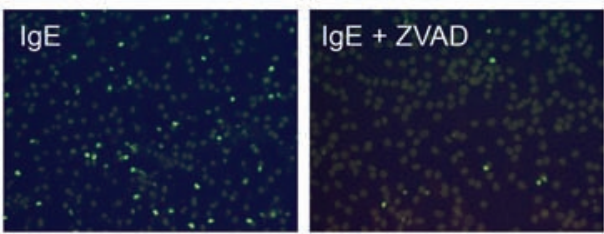
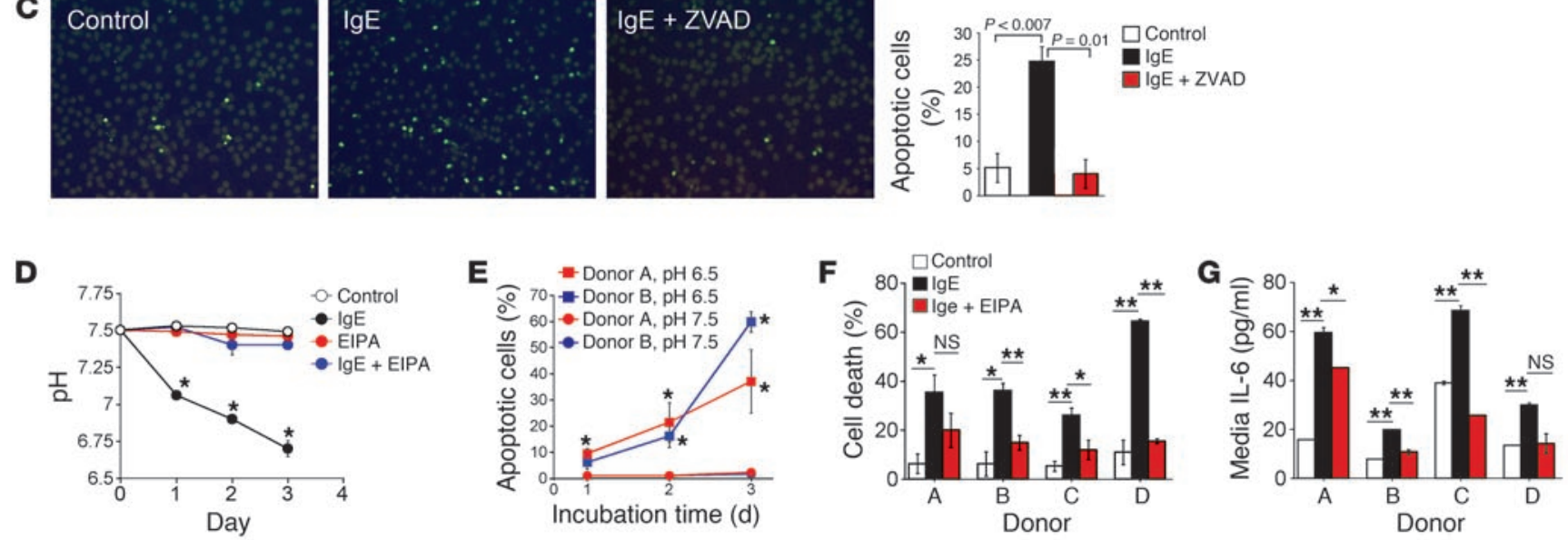

Figure 4

IgE-induced human macrophage apoptosis and cytokine production. IgE (original magnification, $\times 100)$, FceR1 $\alpha(\times 100)$, and TUNEL reactivity $(\times 100)$ localization to $\mathrm{CD}^{+} 8^{+}(\times 40$, insets: $\times 100)$ macrophage-rich area in human atherosclerotic lesions. Serial sections from 2 representative lesions were used for immunostaining (A and B). (A) High levels of IgE and FcER1 $\alpha$ in macrophage-rich areas correlated with increased TUNELpositive cells. (B) Low levels of IgE and FceR1 $\alpha$ in macrophage-rich areas correlated with few TUNEL-positive cells (arrows). (C) Fluorescence TUNEL staining detected human monocyte-derived macrophage apoptosis (fluorescent cells) after 3 days of stimulation with or without human IgE $(50 \mu \mathrm{g} / \mathrm{ml})$ or caspase inhibitor ZVAD-FMK (ZVAD) $(20 \mu \mathrm{M})$. Representative figures are shown $(\times 100)$. Data are mean \pm SEM from 6 experiments using macrophages from the same donor. (D) IgE-induced macrophage RPMI medium pH reduction. Inhibition with NHE1 inhibitor EIPA $(10 \mu \mathrm{M})$ blocked $\mathrm{lgE}$-induced $\mathrm{pH}$ reduction. EIPA alone was used as experimental control. Data are mean \pm SEM from 4 donors. ${ }^{*} P<0.0001$ compared with untreated cells. (E) pH-dependent apoptosis (by TUNEL staining) of human macrophages from different donors. Each treatment used macrophages from 2 donors (A and $\mathbf{B})$. ${ }^{*} P<0.04, \mathrm{pH} 6.5$ versus $\mathrm{pH}$ 7.5. (F and $\mathbf{G}$ ) IgE-induced cell death (by MTT assay) and IL-16 production from macrophages from 4 donors $(\mathbf{A}-\mathbf{D})$. Data are mean \pm SEM from 4 experiments in $\mathbf{E}-\mathbf{G}$. ${ }^{*} P<0.03$, ${ }^{* *} P<0.01$. A final concentration of $50 \mu \mathrm{g} / \mathrm{ml}$ purified human IgE was used for all experiments.

macrophage apoptosis by releasing cytochrome $c$ from the mitochondria to the cytoplasm (31). Immunoblot analysis demonstrated the disappearance of cytochrome $c$ in mitochondria preparation and enhanced cytoplasm Bax from IgE-stimulated macrophages (Figure 5C). As in human macrophages, IgE-induced mouse macrophage death was also impaired significantly when cells were maintained under neutral ( $\mathrm{pH} 7.5$ ) conditions (Figure 5D). IgE activity-associated IL-6 production (Figure 5A) or apoptosis (Figure 5B) of macrophages may have affected NHE1 activity but did not affect its expression. Mouse macrophages showed no differences in NHE1 protein levels after IgE stimulation at different time points (Figure 5E). Indeed, RT-PCR detected no aortic tissue Nhe1 mRNA level changes in atherosclerotic lesions between $A p o e^{-/}$ ${\text { Fcer } 1 \mathrm{a}^{+/+} \text {mice and Apoe }}^{-/-}$Fcer1a $\mathrm{a}^{-/-}$mice (Figure 5F), but both IL-6 (Figure 2E) and apoptosis (Figure 2F) differed significantly between the groups. To confirm further a role of NHE1 in IgE biology, we stimulated peritoneal macrophages from $\mathrm{Nhe}^{+/-}$mice (32), and the experiments yielded results similar to those from EIPAtreated cells. Absence of one Nhe1 allele led to dramatic reduction in IL-6 production and cell death and did not change $\mathrm{pH}$ in IgEtreated macrophages (Figure 5G).

Different forms of IgE in macrophage activation. Aggregated forms of IgE are highly cytokinergic, while monomeric forms of IgE are poorly cytokinergic. The IgE we used in our mouse macrophage study was aggregated and cytokinergic (SPE-7) - usually more potent than monomeric, poorly cytokinergic IgE (e.g., H1 DNP$\varepsilon-206)$ in stimulating mast cells. While SPE-7 stimulates mast cell signal transduction, IL-6 production, histamine release, or survival, H1 DNP-ع-206 appears to have much weaker activity or no activity (33). Antigens or anti-IgE antibodies often are needed to crosslink 
A

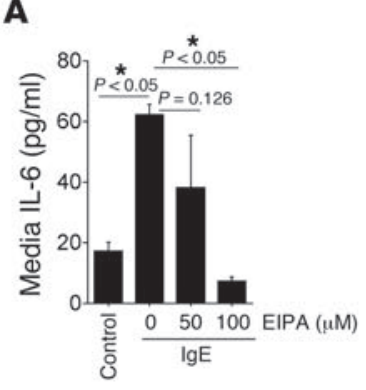

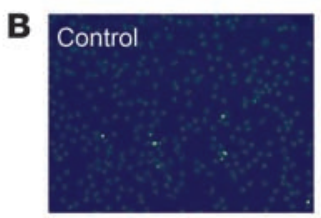

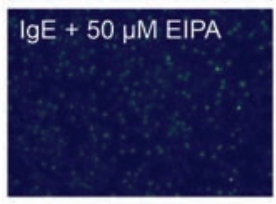

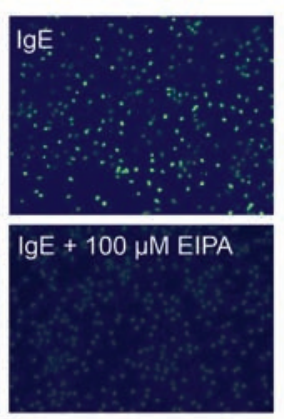
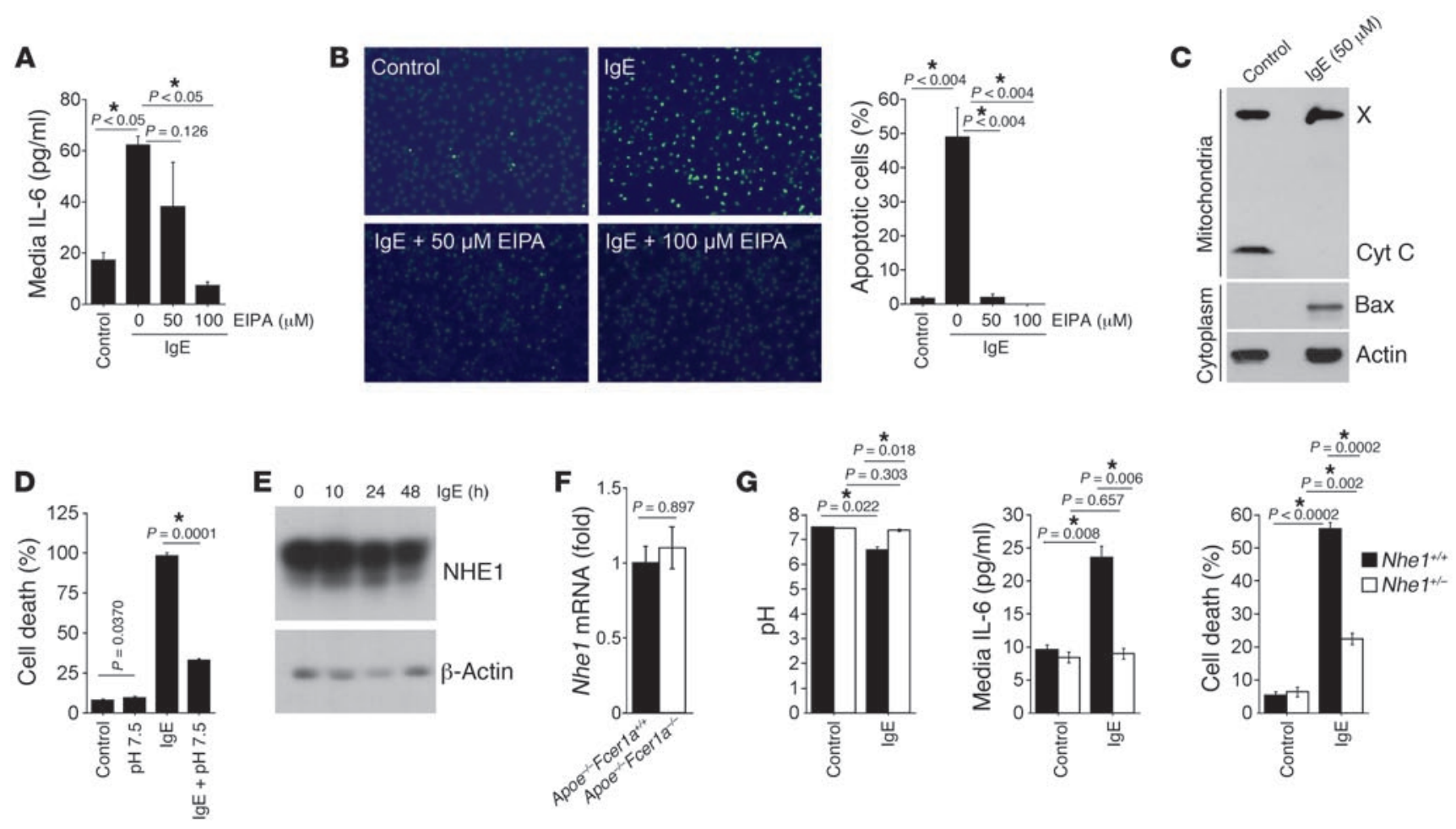

\section{Figure 5}

NHE1 activity-dependent mouse peritoneal macrophage cytokine production and apoptosis. (A) Culture medium IL-6 in macrophages treated with and without IgE and different concentrations of NHE1 inhibitor EIPA. (B) IgE-induced macrophage apoptosis (TUNEL staining) and inhibition with different concentrations of EIPA. Data are mean \pm SEM from 6 experiments. $P<0.05$. Representative figures are shown (original magnification, $\times 100)$. (C) Immunoblot analysis to detect IgE-treated macrophage mitochondria cytochrome $c($ Cyt $C)$ and cytosol Bax. X denotes a protein crossreacting with the cytochrome $c$ antibody. (D) Macrophage cell death under different conditions. (E) NHE1 immunoblot in macrophages treated with IgE for different times. (F) RT-PCR to detect Nhe1 mRNA levels in atherosclerotic lesions from different mice. (G) pH change, IL-6 production, and cell death of macrophages from Nhe $1^{+/+}$mice and $\mathrm{Nhe} 1^{+/-}$mice after 3 days of treatment without (Control) or with IgE. All experiments used $50 \mu \mathrm{g} / \mathrm{ml}$ mouse IgE (SPE-7). Actin immunoblot was used for protein loading control. Cell death was determined with a MTT assay on a 96-well plate with $5 \times 10^{4}$ macrophages per well. Asterisks indicate statistically significant differences.

the $\operatorname{IgE}$ and thereby enhance $\operatorname{IgE}$ activities $(33,34)$. Monomeric IgE H1 DNP-ع-206 may lose its ability to activate macrophages and thus require $\operatorname{IgE}$ antigens. To test these possibilities, we incubated mouse macrophages with $50 \mu \mathrm{g} / \mathrm{ml} \mathrm{H1}$ DNP- $\varepsilon-206$ alone, or highly cytokinergic SPE-7 with and without $10 \mathrm{ng} / \mathrm{ml}$ antigen dinitrophenyl-HSA (DNP-HSA). Both SPE-7 and H1 DNP- -206 significantly reduced $\mathrm{pH}$ (Figure 6A) and promoted macrophage cell death, as determined by MTT assay (Millipore, Figure 6B), but SPE-7 was much more potent than H1 DNP- -206 . In contrast, H1 DNP- -206 more potently promoted macrophage IL- 6 release than SPE-7, as determined by ELISA (Figure 6C). Lower IL-6 production in SPE-7-treated macrophages than in those treated with H1 DNP- -206 may be due to more acidification and cell death in SPE-7-treated cells than in H1 DNP- -206 -treated cells. DNPHSA antigen showed no significant impact on SPE-7 or H1 DNP$\varepsilon-206$ in any of these macrophage activity assays, suggesting that IgE activates macrophages independent of antibody crosslinking.

IgE induced a complex formation between FceR1 and TLR4 (Figure $3 \mathrm{~K}$ ), and absence of TLR and FceR1a yielded the same defects of IgE-induced macrophage signaling transduction, chemokine/ cytokine expression, and apoptosis (Figure 3, F-I). The TLR4 ligand LPS demonstrated a synergistic effect with IgE in inducing mast cell IL-6 production (35). Thus, IgE and LPS may have the same synergistic effect on macrophages. Ox-LDL-induced monocytic cell cytokine/chemokine expression and signal transduction are mediated partially by TLR4 (36). Ox-LDL induces coronary artery EC expression of atherosclerotic vascular calcification molecule BMP-2 via TLR4 (37). These observations suggest a synergistic effect of ox-LDL and IgE in macrophages. We tested this hypothesis by stimulating mouse peritoneal macrophages with 50 $\mu \mathrm{g} / \mathrm{ml} \mathrm{SPE}-7$ with or without $100 \mathrm{ng} / \mathrm{ml} \mathrm{LPS}$ or $50 \mu \mathrm{g} / \mathrm{ml}$ ox-LDL. Data presented in Figure 6D indicate that SPE-7 increased further LPS-induced or ox-LDL-induced IL- 6 production.

Role of IgE in vascular cell biology. IgE and TUNEL activities localized to ECs in the adventitial microvessels and around the lumen and to SMCs in the fibrous cap in human atherosclerotic lesions (Figure 7A), suggesting that IgE interacts with these vascular cells. Cultured human ECs (HuECs) responded to purified human IgE by phosphorylation of p38 and JNK (Figure 7B). Consistent with enhanced phospho-p38 and phospho-JNK, IgE increased levels of cleaved caspase-3 in HuECs (Figure 7C, lanes 2 and 4) and promoted HuEC death in a concentration-dependent manner (Figure 7, D and E). IgE had a minimal effect, however, on HuEC adhesion molecule expression. Both RT-PCR and immunoblot analysis demonstrated low levels of ICAM-1 expression and negligible VCAM-1 expression after IgE stimulation (Supplemental Figure 4). 

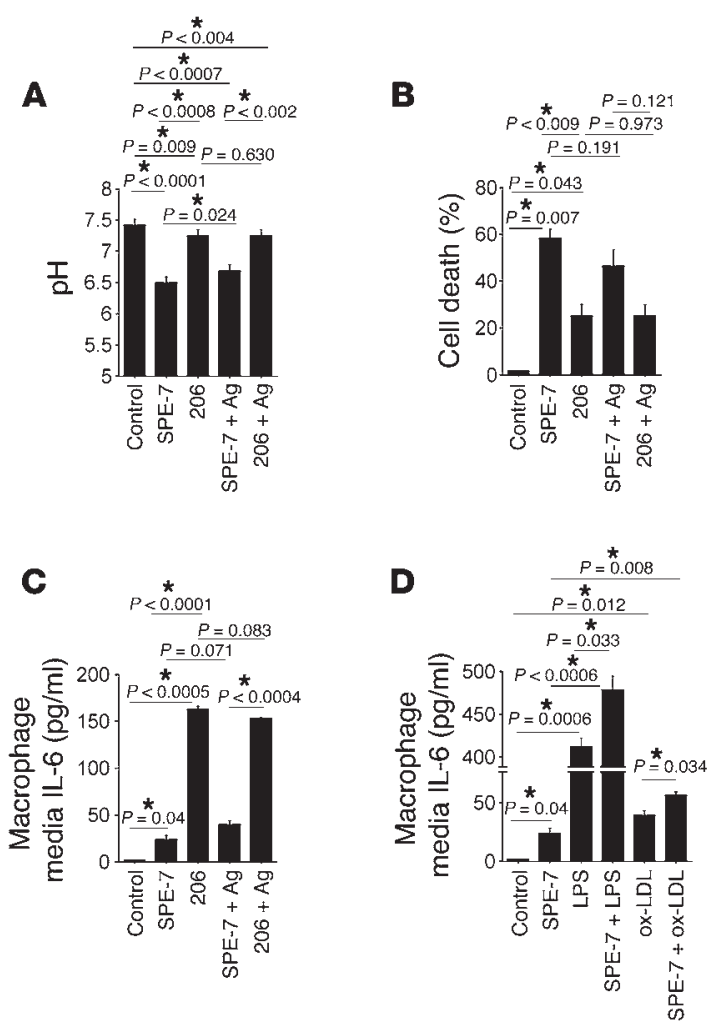

HuSMCs responded similarly to IgE. After 15 minutes of exposure to $100 \mu \mathrm{g} / \mathrm{ml}$ of human IgE, HuSMCs reached a peak for both p38 and JNK activation (Figure 7F). Incubation of HuSMCs with IgE $(100 \mu \mathrm{g} / \mathrm{ml})$ for 3 days increased the expression of BAX, an inducer of apoptosis (ref. 38 and Figure 7G), and provoked IgE concentration-dependent death of HuSMCs (Figure 7, H and I). As in macrophages, after approximately 15-30 minutes of treatment with $100 \mu \mathrm{g} / \mathrm{ml}$ of human IgE, HuSMCs produced high amounts of NF-KB phospho-p65 and phospho-ERK1/2 (Figure 7J). Consistent with increased activation of these signaling molecules, IgE induced the expression of the HuSMC proinflammatory cytokines IFN- $\gamma$, TNF- $\alpha$, and IL-6 (Figure 7K) and cysteinyl cathepsins B, S, L, and K (Figure 7L). IgE may participate in atherogenesis by promoting apoptosis and by enabling cytokine, chemokine, and protease expression in macrophages, SMCs, ECs, and possibly other cells. $\operatorname{IgE}$ activity requires functional FceR1 and TLR4, and IgE may be responsible for reduced $\mathrm{pH}$ - which induces macrophage and vascular cell apoptosis - in human atherosclerotic lesions.

\section{Discussion}

This study established a direct role of $\operatorname{IgE}$ in atherogenesis. The initial observation prompting this extensive study was that serum IgE levels were elevated in two independent Chinese coronary patient populations (from the Central and Eastern regions of the country). Previously, high serum IgE levels were also detected in AMI patients in several populations of European descent $(39,40)$, but whether human atherosclerotic lesions also contain IgE and the receptor necessary for its cellular actions (the high-affinity FceR1), and whether IgE directly affects the cellular pathways relevant to the pathogenesis of the disease, had not been studied. This study demonstrated that in human atherosclerotic lesions, IgE and its recep-

\section{Figure 6}

Different IgE in macrophage activation. $\mathrm{pH}$ change $(\mathbf{A})$, cell death (B), and IL- 6 production $(\mathbf{C})$ in mouse macrophages treated with highly cytokinergic SPE-7 $(50 \mu \mathrm{g} / \mathrm{ml})$ or poorly cytokinergic H1 DNP- $\varepsilon-206$ (206; $50 \mu \mathrm{g} / \mathrm{ml}$ ) with or without antigen (Ag; $10 \mathrm{ng} / \mathrm{ml} \mathrm{DNP-HSA).} \mathrm{(D)}$ Synergistic effect of SPE-7 $(50 \mu \mathrm{g} / \mathrm{ml})$ with LPS $(100 \mathrm{ng} / \mathrm{ml})$ or ox-LDL $(50 \mu \mathrm{g} / \mathrm{ml})$ in macrophage IL-6 production. Cell death and media IL-6 were determined by MTT assay and ELISA, respectively. Asterisks indicate statistically significant differences.

tor FceR1 localized to macrophages in the shoulder regions and lipid cores, to SMCs in the fibrous cap, and to ECs in the lumen and microvessels. Absence of the IgE receptor subunit FceR $1 \alpha$ reduced atherosclerotic lesion sizes in $A p o e^{-/-}$mice by more than $75 \%$ in the thoracic-abdominal aorta and by more than $55 \%$ at the aortic arch. More surprising discoveries came from the mechanistic studies: First, IgE induced macrophage MAPK activation, inflammatory cytokine and chemokine expression, and apoptosis via cooperative activities of FceR1 and TLR4, but not TLR2. These two previously unrelated cell surface receptors formed complexes after IgE stimulation. IgE was inactive in the absence of either receptor. Second, a prior study (29) showed that the average $\mathrm{pH}$ in human atherosclerotic lesions $(\mathrm{pH} \sim 7.55)$ is higher than that in normal human umbilical arteries $(\mathrm{pH} \sim 7.24)$. The $\mathrm{pH}$ in macrophage-rich lipid cores, however, is significantly lower $(\mathrm{pH} \sim 7.15)$ than in any other areas in lesions from the same patients, including calcified areas with or without thrombosis ( $\mathrm{pH}$ 7.73). Acidic $\mathrm{pH}$ in the lipid cores enhanced the binding of phospholipase A2-modified LDL particles to aortic proteoglycans and consequent uptake by macrophages for foam cell formation (30). Further, macrophage apoptosis often appears at the edges of these lipid cores in human atherosclerotic lesions (41), though these observations remain unexplained. The current study links increased IgE and its receptor FceR1 in macrophages from human atherosclerotic lesions with IgE-induced NHE1 activation of macrophages, which reduced extracellular $\mathrm{pH}$ and caused cell death (Figure 4, A and B).

In this study, we tested dose responses to mouse and human IgE of various cell types. For example, as shown in Figure 3B, phosphorylation of mouse macrophage ERK $1 / 2$, JNK, and p38 showed a clear dose curve in response to IgE - from 6.25 to $100 \mu \mathrm{g} / \mathrm{ml}$. In HuECs, phosphorylation of the studied signaling molecules did not show clear dose responses (Figure 7B), but $100 \mu \mathrm{g} / \mathrm{ml}$ human IgE yielded the lowest survival of ECs (Figure 7D) and SMCs (Figure $7 \mathrm{I}$ ). We selected $50 \mu \mathrm{g} / \mathrm{ml} \mathrm{IgE}$ to induce mouse and human macrophage signal transduction, apoptosis, and inflammatory cytokine, chemokine, and protease expression and $100 \mu \mathrm{g} / \mathrm{ml}$ human IgE to activate human SMCs and ECs. These observations prompted questions: For example, we showed in this study that IgE stimulated the death of macrophages, ECs, and SMCs, but it promoted mast cell survival in several other studies $(33,42)$. These different phenotypes in mast cells and macrophages might be due to differences in expression of FceR1 $\beta$-chain. Mast cells but not macrophages express FceR1 $\beta$-chain (43). Although monocytes also express low levels of FceR $1 \beta$-chain, this subunit completely disappeared after these cells matured and became macrophages, as detected by immunoblot analysis with anti-human MS4A2 (FcER1 $\beta$ ) mouse monoclonal antibody (1:1,000, Abcam) (data not shown). Absence of FceR1 $\beta$-chain may cause conformational differences in FceR1 in macrophages (7) compared with mast cells, thereby leading to different responses to $\operatorname{IgE}$ - a hypothesis that 
A

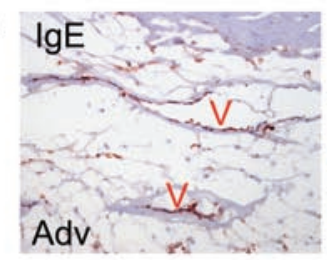

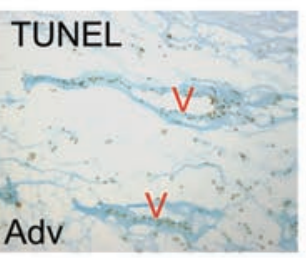

C

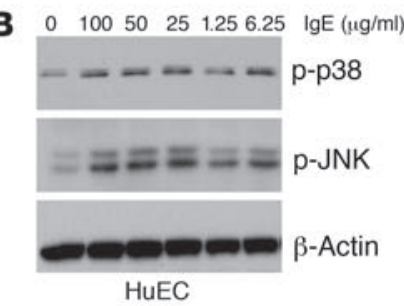

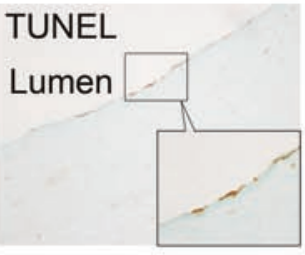

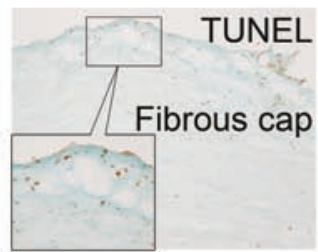

D

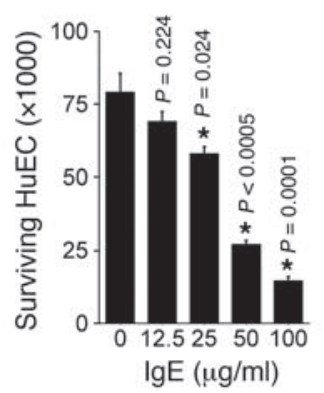

E

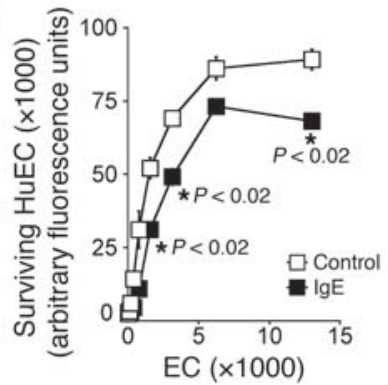

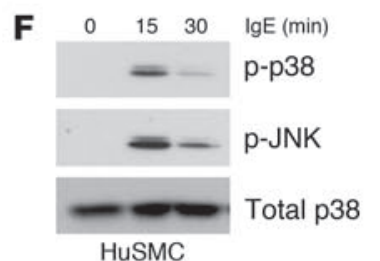

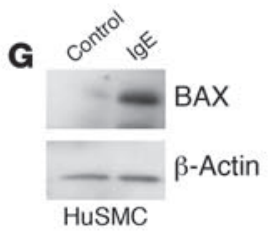

HuSMC
H

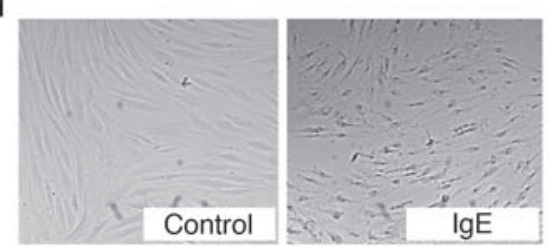

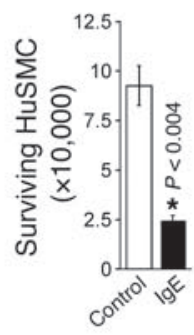

K

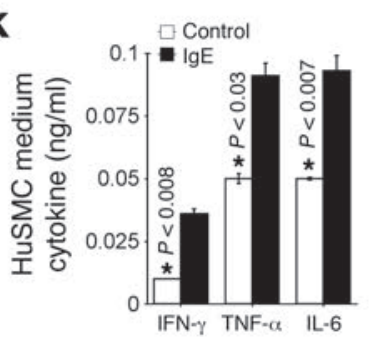

L

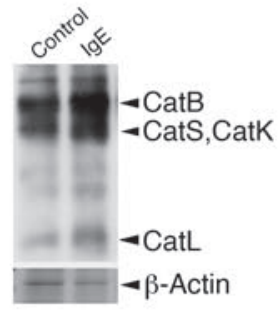

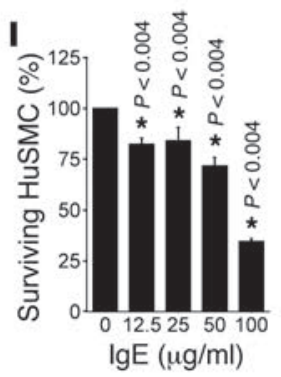

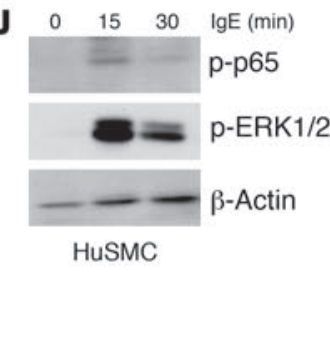

Casp-3

$\beta$-Actin

. 
CHD subjects suggest that the slightly elevated serum IgE levels (all $<2.5 \mu \mathrm{g} / \mathrm{ml}$ ) in CHD patients may not be of pathogenetic significance per se. Under some conditions, however, systemic IgE may reach pathogenic levels. Parasitic infection (e.g., Paragonimus westermani) enhances mouse serum IgE levels to approximately 50 $\mu \mathrm{g} / \mathrm{ml}$ (44). Patients with the hyperimmunoglobulin E recurrent infection syndrome (HIES) have serum IgE levels of approximately $72-86 \mu \mathrm{g} / \mathrm{ml}(45)$. Although HIES is a non-atherosclerotic arterial disease, high systemic IgE levels lead to vascular pathology, including vasculitis, thrombosis, vascular ectasia, and aneurysms in the coronary, aortic, carotid, and cerebral arteries $(45,46)$. Thus, we may envision that in areas rich in macrophages and vascular ECs and SMCs within human atherosclerotic lesions (i.e., in an environment with multiple initiators of chronic inflammatory reactions), increased IgE levels (Figure 1, A-C) and enhanced FceR1 expression (Figure 4A) may have adjuvant activity that further activates these cells that are pertinent to atherogenesis.

Prior studies have demonstrated that MCs and macrophages - as well as dendritic cells, monocytes, and eosinophils - express FceR1 (5-8). These cells also dwell in human atherosclerotic lesions. It remains uncertain, however, whether and how $\operatorname{IgE}$ affects the biology of these atherosclerosis-pertinent cells. In atherosclerotic lesions, dendritic cells, monocytes, and eosinophils can be stimulated via several mechanisms, including inflammatory mediators from macrophages or lymphocytes (47). Although not a canonical activator of these other cell types, IgE might nonetheless cooperate in their stimulation. For example, as described above, IgE affects dendritic cell TNF- $\alpha$ and IL-10 expression, as well as antigen presentation $(6,10)$ - all functions involved in atherogenesis. Crosslinking of dendritic cell FceR1 $\alpha$ with anti-FceR1 $\alpha$ monoclonal antibodies results in the production of the $\mathrm{T}$ cell chemoattractant CCL28, thereby enhancing IL-13-producing CD4+ $\mathrm{T}$ cell recruitment to the site of viral infection in mouse lungs (5). The same phenomenon may occur in human atherosclerotic lesions. IgEmediated dendritic cell chemokine and cytokine expression may promote leukocyte infiltration and activation, a hypothesis that requires further experimentation in vitro and in animal models. High numbers of MCs have been found at sites of atheromatous erosion or rupture in coronary plaques of patients with AMI (16), and mast cells are known to express FceR1. IgE-induced MC activation is only one of the many pathways triggering $\mathrm{MC}$ release of inflammatory mediators (48), which contribute to the development of atherosclerosis (4). In experimental models of mouse atherosclerosis, $\mathrm{MC}$ activation with antigen sensitization, with the neuropeptide substance $P$, or with compound $48 / 80$ has enhanced atherogenesis $(49,50)$. Therefore, reduced atherosclerosis in the Apoe $e^{-/-} \mathrm{Fcerla}^{-/-}$mice in our study may have resulted from combinational defects of IgE-mediated responses on all cells expressing this high-affinity IgE receptor.

Vascular SMCs and ECs expressed FceR1 under inflammatory conditions (Figure 1D). IgE induced signal transduction, inflammatory cytokine production, and apoptosis in these vascular cells (Figure 7), as it did in macrophages (Figure 3), but the IgE and FceR1 $\alpha$ immunoreactivities on ECs or SMCs in human atherosclerotic lesions were much weaker than those of macrophages (Figure 1, A-C, and Figure 7A). Although not tested, IgE functions (e.g., cytokine production and apoptosis) on these vascular cells may not be as profound as on macrophages within atherosclerotic lesions. Other mechanisms may be more important than IgE - for example, inflammatory cytokines from macrophages, MCs, lymphocytes, or other inflammatory cells may induce vascular cell pathologic gene expression (51). Inflammatory cytokines (52), cathepsins (53), and MC proteases (54) in atherosclerotic lesions may also cause vascular cell apoptosis. Therefore, IgE may participate in EC and SMC inflammatory responses, but its importance and significance remain to be evaluated with more in vivo experiments.

Atherosclerotic lesions contain few IgE-producing B cells, and these appear in the adventitia or early fatty streaks $(55,56)$. Few B cells localize in the human atherosclerotic intima (57), a region that stains vividly for $\operatorname{IgE}$ in the vicinity of macrophages and SMCs. Therefore, the source of $\operatorname{IgE}$ found in the intima and the mechanism by which IgE accumulates in the intima - and specifically, to the sites where macrophages and SMCs cluster - remain unknown, although hyperpermeable endothelium on plaque surfaces or in the fragile microvessels in neovascularized areas of plaques, or intra-plaque hemorrhages therein, might permit accelerated entry of IgE from blood. Sustained cellular binding of IgE may then promote protease expression by lesional macrophages (51) and boost local inflammatory cytokine levels (58).

In the present study, age, serum HDL levels, sex, and history of diabetes mellitus were significantly different between non-CHD subjects and CHD patients in both Central and Eastern Chinese populations. After adjustment for clinical presentation and HDL levels, sex, and history of diabetes mellitus, both fasting glucose levels and IgE were significantly higher in AMI and UAP patients than in SAP patients and non-CHD subjects. These results, from relatively small patient populations along with a previous casecontrolled study (40), are hypothesis generating and require further investigation in larger populations. Yet these clinical data support the in vivo relevance of the reduced atherosclerosis in Fcerl $1 a^{-/-}$mice and mechanistic studies described herein.

Together, increased IgE levels in human atherosclerotic lesions and in serum from patients with unstable plaques support the notion that such "minor" immunoglobulin molecules may participate in the activation not only of MCs, but also other bloodborne inflammatory cells, such as monocytes, macrophages, and dendritic cells, and even vascular ECs and SMCs, during the pathogenesis of human atherosclerosis.

\section{Methods}

Patient selection. From July to October 2008, 362 patients admitted consecutively to the Department of Cardiology at the Second Affiliated Hospital, College of Medicine, Zhejiang University, Hangzhou, China, were enrolled due to their clinical symptoms of chest pain, dyspnea, precordial discomfort, or cardiac dysfunction as defined by an ejection fraction less than $50 \%$ on echocardiography or electrocardiogram abnormalities including ST-T changes and arrhythmia. Given the known association of $\operatorname{IgE}$ with allergic diseases, cancer, and autoimmunity, we excluded patients with the following conditions to limit potential confounding effects: asthma $(n=22)$, allergic dermatitis $(n=3)$, history of allergic diseases $(n=25)$, arthritis $(n=3)$, cancer $(n=5)$, renal failure $(n=34)$, chronic hepatic disease $(n=25)$, rheumatic heart disease $(n=2)$, valvular heart disease $(n=2)$, or other cardiac diseases $(n=1)$. The remaining 240 subjects were invited to have digital subtractive coronary angiography (DSA, FD 20, Phillips Medical Systems). Of these, 147 patients had CHD, defined by one or more main coronary arteries with at least $50 \%$ stenosis. Of the subjects with $\mathrm{CHD}, 116 \mathrm{had}$ an acute coronary syndrome, including 33 with AMI, diagnosed by 2 -fold increases in creatinine kinase-MB levels and 5-fold increases in troponin-I levels relative to the respective upper reference limit, ischemic symptoms, or ST-T changes in electrocardiography indicative of ischemia and/or infarction; 83 with UAP, 
diagnosed with the progression of ischemic symptoms less than 3 months before admission to the hospital; and 31 with SAP, diagnosed by predictable exertional chest discomfort more than 3 months before enrollment. A total of 93 patients with no or less than 50\% luminal narrowing of the coronary artery were selected as non-CHD controls.

The same patient selection method was used at the College of Life Science and Technology and Center for Human Genome Research, Huazhong University of Science and Technology, Wuhan, China. The study enrolled 1,413 patients from several hospitals in Central China (individuals enrolled in hospitals in Wuhan city were from Hubei province, Hunan province, Anhui province, and Henan province). A total of 431 patients were excluded due to asthma $(n=79)$, allergic dermatitis $(n=18)$, history of allergic diseases $(n=124)$, arthritis $(n=8)$, cancer $(n=13)$, renal failure $(n=89)$, chronic hepatic disease $(n=45)$, rheumatic heart disease $(n=36)$, valvular heart disease $(n=13)$, or other cardiac diseases $(n=6)$. Of the remaining 982 subjects, 709 were diagnosed with CHD, and 273 with no or less than $50 \%$ luminal narrowing of the coronary artery were selected as non-CHD controls. Among the 709 patients with CHD, 462 had acute coronary syndrome, including 207 with AMI, 255 with UAP, and 247 with SAP.

Patient information recording and sample collection. Patient information was recorded, including age, sex, height, weight, BMI, history of hypertension, history of diabetes, and smoking (consuming tobacco for $>3$ years). Blood samples were extracted from the sheath in the radial or femoral artery during the procedure for IgE measurement. Blood samples were prepared from the vein for serum TC, TG, LDL, HDL, and fasting glucose levels, which were determined using standard laboratory procedures (Olympus AU5400 automated analyzer) at the clinical laboratory of the Second Affiliated Hospital or the clinical laboratory of Union Hospital, Tongji Medical College of Huazhong University of Science and Technology. Venous blood was collected after a fast of at least 12 hours. Serum sample aliquots were stored at $-80^{\circ} \mathrm{C}$.

IgE chemiluminescence determination. Human serum IgE levels were detected using a chemiluminescence immunoassay (Unicel DXI800, Beckman Coulter), according to the manufacturer's instructions. IgE levels of arterial and venous blood were not significantly different.

Immunohistology. Atherosclerotic and non-atherosclerotic human carotid arteries were obtained from transplant donors at endarterectomy or at autopsy, according to protocols preapproved by the Human Investigative Review Committee of Harvard Medical School. Serial cryostat sections $(6 \mu \mathrm{m})$ were prepared and stained for CD68 (macrophages, 1:500, Dako), CD31 (ECs, 1:35, Dako), $\alpha$-actin (SMCs, 1:40, Enzo Diagnostics), $\operatorname{IgE}(1: 50$, Novus Biologicals), and FceR1 $\alpha$ (1:50, Santa Cruz Biotechnology Inc.) antibodies. Apoptotic cells in human atherosclerotic lesions were detected using an ApopTag Plus Peroxidase In Situ Apoptosis Detection Kit, according to the manufacturer's instructions (Millipore).

Animal protocols and atherosclerotic lesion characterization. We crossbred Fcer1 $1 a^{-/}$mice (C57BL/6, N9, provided by Marie-Helene Jouvin and JeanPierre Kinet of Beth Israel Deaconess Medical Center and Harvard Medical School, Boston, Massachusetts, USA) (20) with Apoe $e^{-/-}$mice (C57BL/6,

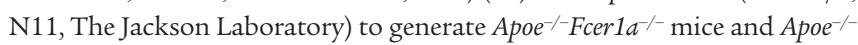
Fcer1 $1 a^{+/+}$control mice. All mice used in this study were littermates and syngeneic in the C57BL/ 6 background. To induce atherosclerosis, we fed 10-week-old males from each group a Western diet (Research Diets Inc.) for 12 weeks. Lesion characterizations, including thoracic-abdominal aorta oil red $\mathrm{O}$ staining, aortic arch lesion intima and media areas, lesion macrophages (Mac-3), T cells (CD4 and CD3; both antibodies yielded similar staining), IL-6 (Abcam), MHC class II-positive cells, and TUNEL-positive apoptotic cells (ApopTag Plus Peroxidase In Situ Apoptosis Kit), were performed as previously described (17). Images were captured by a digital system, the staining area was measured using computer-assisted image quanti- fication (Image-Pro Plus software, Media Cybernetics), and immunopositive cells were counted manually. All mouse experiments were performed, and data were analyzed in a blinded fashion, by at least 3 observers.

Cell culture. Human macrophages were prepared by differentiating Ficoll gradient-separated monocytes from human blood in RPMI with $10 \%$ human serum (Gemini Bio-Products) for 10 days on Falcon Primaria tissue culture dishes (BD) without coating. Mouse thioglycolate-stimulated (3\%, Sigma-Aldrich) peritoneal macrophages were prepared from WT C57BL/6 mice (The Jackson Laboratory), Fcer1 $1 a^{-/-}$mice (congenic C57BL/6, N>8) (21), Tlr2 ${ }^{-/-}$mice (The Jackson Laboratory, N16), and Tlr4 ${ }^{--}$mice (The Jackson Laboratory, C57BL/6, N8). Cells were cultured in RPMI-1640 with $10 \%$ FBS. HuSMCs and ECs were obtained from human donor aortas and subcultured at passages 2-5 in DMEM containing 10\% FBS (for SMCs) or in medium 199 containing 20\% FBS (for ECs).

Cytokine production and protease expression. For detection of cytokine production, cells were starved in corresponding media containing $0.5 \%$ FBS overnight, then incubated for 2 days in starvation media containing $\operatorname{IgE}$ (50 $\mu \mathrm{g} / \mathrm{ml}$ for macrophages; $100 \mu \mathrm{g} / \mathrm{ml}$ for SMCs and ECs). Mouse poorly cytokinergic monomeric IgE H1 DNP- $\varepsilon-206(50 \mu \mathrm{g} / \mathrm{ml})(33)$ and highly cytokinergic aggregated IgE SPE-7 $(50 \mu \mathrm{g} / \mathrm{ml})$ (Sigma-Aldrich) with or without LPS $(100 \mathrm{ng} / \mathrm{ml})$, ox-LDL $(50 \mu \mathrm{g} / \mathrm{ml})$, or DNP-HSA $(10 \mathrm{ng} / \mathrm{ml})$ were used to stimulate mouse macrophages. Human IgE was obtained from Immunology Consultants Laboratory Inc. (RA-80E). Unless otherwise indicated, all mouse macrophages were treated with SPE-7. Both cells and culture media were collected to detect IL- 6 and MCP- 1 by real-time PCR (Bio-Rad) and ELISA (BD), according to the manufacturers' instructions. Cells were lysed in a $\mathrm{pH} 5.5$ lysis buffer containing $1 \%$ Triton X-100, $40 \mathrm{mM}$ sodium acetate, and $1 \mathrm{mM}$ EDTA to detect active cysteine proteases by active site JPM labeling, according to a protocol reported previously (17).

Immunoprecipitation and immunoblot analysis. For immunoprecipitation, mouse macrophages were starved overnight in RPMI containing $0.5 \% \mathrm{FBS}$, followed by the addition of purified mouse $\operatorname{IgE}(50 \mu \mathrm{g} / \mathrm{ml}$, Sigma-Aldrich) for 15 minutes. Cells were lysed in a RIPA buffer containing $50 \mathrm{mM}$ Tris, $\mathrm{pH}$ 7.4, $150 \mathrm{mM} \mathrm{NaCl}, 2 \mathrm{mM}$ EDTA, $1 \% \mathrm{NP}-40,0.1 \% \mathrm{SDS}, 5 \mu \mathrm{g} / \mathrm{ml}$ aprotinin, $5 \mu \mathrm{g} / \mathrm{ml}$ leupeptin, and $1 \mathrm{mM}$ phenylmethylsulfonyl fluoride. Lysates were precleared for 1 hour with protein $\mathrm{A} / \mathrm{G}$ agarose (Santa Cruz Biotechnology Inc.), followed by incubation overnight with $1 \mu \mathrm{g}$ mouse FceR1 $\alpha$ or TLR 4 polyclonal antibody (Santa Cruz Biotechnology Inc.) and protein A/G agarose for an additional hour. Immunoprecipitates were then washed with $4 \times 1 \mathrm{ml}$ cell lysis buffer, followed by separation on $8 \%$ SDS-PAGE for immunoblot analysis with rabbit anti-mouse TLR4 or FceR1 $\alpha$ polyclonal antibody (1:1,000, Santa Cruz Biotechnology Inc.).

For immunoblot analysis, an equal amount of protein from each cell type preparation was separated by SDS-PAGE, blotted, and detected with different antibodies, including FceR1 $\alpha$ (1:1,000, Santa Cruz Biotechnology Inc.), phospho-ERK1/2 (rabbit anti-mouse ERK1/2 Thr202/Thr204, 1:1,000, Cell Signaling Technology), phospho-JNK (rabbit anti-mouse phospho-Thr/Pro/Tyr-JNK, 1:1,000, Promega), $\beta$-actin (goat anti-mouse $\beta$-actin, 1:3,000, Santa Cruz Biotechnology Inc.), phospho-p38 MAPK (Thr180/Tyr182, 1:1,000, Cell Signaling Technology), phospho-p65 (NF-кB p65 Ser536, 1:1,000, Cell Signaling Technology), cleaved caspase-3 (1:1,000, Cell Signaling Technology), Bax (1:1,000, Santa Cruz Biotechnology Inc.), TLR4 (1:1,000, Santa Cruz Biotechnology Inc.), NHE1 (1:1,000, Millipore), and $\beta$-actin (1:3,000, Santa Cruz Biotechnology Inc.).

Cell death analysis. To detect IgE-induced apoptosis, we cultured human and mouse macrophages, HuECs, and HuSMCs on 8-well chamber slides, 96-well plates, or 6-well plates precoated with $1 \%$ gelatin. After overnight starvation, cells were stimulated with $\operatorname{IgE}(50 \mu \mathrm{g} / \mathrm{ml}$ for macrophages and $100 \mu \mathrm{g} / \mathrm{ml}$ for HuECs and HuSMCs) for approximately 3-4 days before detection of apoptotic cells using TUNEL staining (In Situ Cell Death 
Detection Kit, Roche Diagnostics Corp.), MTT cell proliferation assay (Millipore), or CyQUANT cell proliferation assay (Invitrogen), according to the manufacturers' instructions. For detection of mitochondria cytochrome $c$ release, IgE-stimulated macrophages were lysed in a cytosol extraction buffer mix and homogenized, the supernatant cytosol fraction was separated by centrifugation, and pellet was resuspended in a mitochondria extraction buffer mix, according to the manufacturer's instructions (Abcam, catalog AB65311). Cytosol and mitochondria fractions were separated and immunoblotted for cytochrome $c$ (1:1,000, Abcam) and Bax (1:1,000, Santa Cruz Biotechnology Inc.). In $\mathrm{pH}$ experiments, we used custom-made acidic ( $\mathrm{pH}$ 6.5) and neutral ( $\mathrm{pH}$ 7.5) $\mathrm{pH}$ DMEM (Hyclone, Thermo Scientific) for human macrophages and HEPES-balanced RPMI-1640 medium for mouse macrophages.

Statistics. All data are expressed as mean \pm SEM. For patient serum sample chemiluminescence immunoassay data with normal distribution and homogeneity of variance, independent 2-tailed Student's $t$ test, and 1-way ANOVA least significant difference test were used for the comparison between 2 groups and among multiple groups, respectively. Non-parametric Kruskal-Wallis $H$ test was used for multiple group comparisons with skewed data distribution or heterogeneity of variance. For the ranked data, Fisher's exact test and Pearson $\chi^{2}$ test were used for the comparison between 2 groups and among multiple groups, respectively. To analyze the correlation of serum IgE and other values, we used Pearson's correlation test and an independent 2-tailed Student's $t$ test. To examine the influence of potential confounders to serum IgE levels, we adjusted for age, sex, BMI, hypertension, smoking, diabetes mellitus, fasting glucose, and serum lipid levels using a multiple linear regression model. All in vitro cell culture or animal data were analyzed using non-parametric Mann-Whitney $U$ test due to the small sample size and abnormal data distribution. SPSS version 16 was used for analysis, and $P$ values less than 0.05 were considered statistically significant.

Study approval. Human study protocols were pre-approved by the Hospital Review Committee of Second Affiliated Hospital, College of Medicine, Zhejiang University, and the Human Study Review Committee of the Center for Human Genome Research, Huazhong University of Science and Technology. All patients gave informed consent. Mouse experiments were all approved by the Animal Research Committee of Harvard Medical School.

\section{Acknowledgments}

This study is supported by grants from the National Natural Science Foundation of China (30670867 to M.X. Xiang; 30871067 to X. Cheng), the NIH (HL60942, HL81090, HL88547 to G.P. Shi; and HL34636, HL80472 to P. Libby), and the American Heart Association Established Investigator Award (0840118N to G.P. Shi). Wihuri Research Institute is maintained by the Jenny and Antti Wihuri Foundation, Helsinki, Finland.

Received for publication December 6, 2010, and accepted in revised form June 15, 2011.

Address correspondence to: Guo-Ping Shi, Cardiovascular Medicine, Brigham and Women's Hospital, 77 Avenue Louis Pasteur, NRB-7, Boston, Massachusetts 02115, USA. Phone: 617.525.4358; Fax: 617.525.4380; E-mail: gshi@rics.bwh.harvard.edu.
1. Kinet JP. The high-affinity IgE receptor (Fc epsilon RI): from physiology to pathology. Annu Rev Immunol. 1999;17:931-972.

2. Gould HJ, Sutton BJ. IgE in allergy and asthma today. Nat Rev Immunol. 2008;8(3):205-217.

3. Leslie M. Mast cells show their might. Science. 2007;317(5838):614-616

4. Sun J, et al. Mast cells promote atherosclerosis by releasing proinflammatory cytokines. Nat Med. 2007;13(6):719-724.

5. Grayson $\mathrm{MH}$, et al. Induction of high-affinity $\operatorname{IgE}$ receptor on lung dendritic cells during viral infection leads to mucous cell metaplasia. J Exp Med. 2007;204(11):2759-2769.

6. Le $\mathrm{T}$, et al. Interferons modulate Fc epsilon RIdependent production of autoregulatory IL-10 by circulating human monocytoid dendritic cells. J Allergy Clin Immunol. 2009;123(1):217-223.

7. Dombrowicz D, Quatannens B, Papin JP, Capron A, Capron M. Expression of a functional Fc epsilon $\mathrm{RI}$ on rat eosinophils and macrophages. J Immunol. 2000;165(3):1266-1271.

8. Katoh N, Kraft S, Wessendorf JH, Bieber T. The high-affinity IgE receptor (FcepsilonRI) blocks apoptosis in normal human monocytes. $J$ Clin Invest. 2000;105(2):183-190.

9. Mancardi DA, Iannascoli B, Hoos S, England P, Daëron M, Bruhns P. FcgammaRIV is a mouse IgE receptor that resembles macrophage FcepsilonRI in humans and promotes IgE-induced lung inflammation. J Clin Invest. 2008;118(11):3738-3750.

10. Bieber T. Fc epsilon RI on human epidermal Langerhans cells: an old receptor with new structure and functions. Int Arch Allergy Immunol. 1997; 113(1-3):30-34.

11. Laukkanen J, Lehtolainen P, Gough PJ, Greaves DR, Gordon S, Ylä-Herttuala S. Adenovirus-mediated gene transfer of a secreted form of human macrophage scavenger receptor inhibits modified low-density lipoprotein degradation and foamcell formation in macrophages. Circulation. 2000; 101(10):1091-1096.
12. Jalkanen J, Leppänen $P$, Närvänen $O$, Greaves $D R$, Ylä-Herttuala S. Adenovirus-mediated gene transfer of a secreted decoy human macrophage scavenger receptor (SR-AI) in LDL receptor knock-out mice. Atherosclerosis. 2003;169(1):95-103.

13. Moore KJ, et al. Loss of receptor-mediated lipid uptake via scavenger receptor A or CD36 pathways does not ameliorate atherosclerosis in hyperlipidemic mice. J Clin Invest. 2005;115(8):2192-2201.

14. Devries-Seimon T, et al. Cholesterol-induced macrophage apoptosis requires ER stress pathways and engagement of the type A scavenger receptor. J Cell Biol. 2005;171(1):61-73.

15. Michelsen KS, et al. Lack of Toll-like receptor 4 or myeloid differentiation factor 88 reduces atherosclerosis and alters plaque phenotype in mice deficient in apolipoprotein E. Proc Natl Acad Sci U S A. 2004;101(29):10679-10684

16. Mullick AE, Tobias PS, Curtiss LK. Modulation of atherosclerosis in mice by Toll-like receptor 2. J Clin Invest. 2005;115(11):3149-3156.

17. Sukhova GK, et al. Deficiency of cathepsin S reduces atherosclerosis in LDL receptor-deficient mice. J Clin Invest. 2003;111(6):897-906.

18. Kovanen PT, Kaartinen M, Paavonen T. Infiltrates of activated mast cells at the site of coronary atheromatous erosion or rupture in myocardial infarction. Circulation. 1995;92(5):1084-1088.

19. Leon ML, Zuckerman SH. Gamma interferon: a central mediator in atherosclerosis. Inflamm Res. 2005;54(10):395-411.

20. Dombrowicz D, Flamand V, Brigman KK, Koller BH, Kinet JP. Abolition of anaphylaxis by targeted disruption of the high affinity immunoglobulin E receptor alpha chain gene. Cell. 1993;75(5):969-976.

21. Tabas I. Consequences and therapeutic implications of macrophage apoptosis in atherosclerosis: the importance of lesion stage and phagocytic efficiency. Arterioscler Thromb Vasc Biol. 2005; 25(11):2255-2264.

22. Eshhar Z, Ofarim M, Waks T. Generation of hybridomas secreting murine reaginic antibodies of anti-
DNP specificity. J Immunol. 1980;124(2):775-780.

23. Lutgens E, et al. Disruption of the cathepsin K gene reduces atherosclerosis progression and induces plaque fibrosis but accelerates macrophage foam cell formation. Circulation. 2006;113(1):98-107.

24. Gao B, Wang Y, Tsan MF. The heat sensitivity of cytokine-inducing effect of lipopolysaccharide. J Leukoc Biol. 2006;80(2):359-366.

25. Akira S, Takeda K. Toll-like receptor signalling. Nat Rev Immunol. 2004;4(7):499-511.

26. Seimon TA, Obstfeld A, Moore KJ, Golenbock DT, Tabas I. Combinatorial pattern recognition receptor signaling alters the balance of life and death in macrophages. Proc Natl Acad Sci U S A. 2006; 103(52):19794-19799.

27. Seimon TA, et al. Atherogenic lipids and lipoproteins trigger CD36-TLR2-dependent apoptosis in macrophages undergoing endoplasmic reticulum stress. Cell Metab. 2010;12(5):467-482.

28. Yu LC, Montagnac G, Yang PC, Conrad DH, Benmerah A, Perdue MH. Intestinal epithelial CD23 mediates enhanced antigen transport in allergy: evidence for novel splice forms. Am J Physiol Gastrointest Liver Physiol. 2003;285(1):G223-G234.

29. Naghavi M, et al. pH Heterogeneity of human and rabbit atherosclerotic plaques; a new insight into detection of vulnerable plaque. Atherosclerosis. 2002;164(1):27-35.

30. Lähdesmäki K, et al. Phospholipase A(2)-modified LDL particles retain the generated hydrolytic products and are more atherogenic at acidic $\mathrm{pH}$. Atherosclerosis. 2009;207(2):352-359.

31. Yang J, et al. Prevention of apoptosis by Bcl-2: release of cytochrome c from mitochondria blocked. Science. 1997;275(5303):1129-1132.

32. Yu L, Quinn DA, Garg HG, Hales CA. Deficiency of the NHE1 gene prevents hypoxia-induced pulmonary hypertension and vascular remodeling. Am J Respir Crit Care Med. 2008;177(11):1276-1284.

33. Kitaura J, et al. Evidence that IgE molecules mediate a spectrum of effects on mast cell survival and activation via aggregation of the FcepsilonRI. Proc 
Natl Acad Sci U S A. 2003;100(22):12911-12916.

34. Matsuda K, et al. Monomeric IgE enhances human mast cell chemokine production: IL-4 augments and dexamethasone suppresses the response. J Allergy Clin Immunol. 2005;116(6):1357-1363.

35. Takenaka $H$, et al. Synergistic augmentation of inflammatory cytokine productions from murine mast cells by monomeric IgE and toll-like receptor ligands. Biochem Biophys Res Commun. 2010;391(1):471-476.

36. Geng H, et al. The effects of ox-LDL in human atherosclerosis may be mediated in part via the toll-like receptor 4 pathway. Mol Cell Biochem. 2010; 342(1-2):201-206

37. Su X, Ao L, Shi Y, Johnson TR, Fullerton DA, Meng X. Oxidized low density lipoprotein induces bone morphogenetic protein-2 in coronary artery endothelial cells via toll-like receptors 2 and 4 . J Biol Chem. 2011;286(14):12213-12220.

38. Gavathiotis E, et al. BAX activation is initiated at a novel interaction site. Nature. 2008; 455(7216):1076-1081.

39. Szczeklik A, Sladek K, Szczerba A, Dropinski J. Serum immunoglobulin E response to myocardial infarction. Circulation. 1988;77(6):1245-1249.

40. Kovanen PT, Mänttäri M, Palosuo T, Manninen V, Aho K. Prediction of myocardial infarction in dyslipidemic men by elevated levels of immunoglobulin classes A, E, and G, but not M. Arch Intern Med. 1998;158(13):1434-1439.

41. Hegyi L, Skepper JN, Cary NR, Mitchinson MJ. Foam cell apoptosis and the development of the lipid core of human atherosclerosis. J Pathol. 1996; 180(4):423-429.
42. Asai K, et al. Regulation of mast cell survival by IgE. Immunity. 2001;14(6):791-800.

43. Donnadieu E, Jouvin MH, Kinet JP. A second amplifier function for the allergy-associated Fc(epsilon)RIbeta subunit. Immunity. 2000;12(5):515-523.

44. Shin MH, Min HK. Effects of anti-IgE mAb on serum IgE, Fc epsilon RII/CD23 expression on splenic $\mathrm{B}$ cells and worm burden in mice infected with Paragonimus westermani. Korean J Parasitol. 1997; 35(1):47-54.

45. King CL, Gallin JI, Malech HL, Abramson SL, Nutman TB. Regulation of immunoglobulin production in hyperimmunoglobulin E recurrent-infection syndrome by interferon gamma. Proc Natl Acad Sci U S A. 1989;86(24):10085-10089.

46. Yavuz H, Chee R. A review on the vascular features of the hyperimmunoglobulin E syndrome. Clin Exp Immunol. 2010;159(3):238-244.

47. Lee WH, et al. Activation of monocytes, T-lymphocytes and plasma inflammatory markers in angina patients. Exp Mol Med. 1999;31(3):159-164.

48. Abramson J, Pecht I. Regulation of the mast cell response to the type $1 \mathrm{Fc}$ epsilon receptor. Immunol Rev. 2007;217:231-254.

49. Bot I, et al. The neuropeptide substance P mediates adventitial mast cell activation and induces intraplaque hemorrhage in advanced atherosclerosis. Circ Res. 2010;106(1):89-92.

50 . Bot I, et al. Perivascular mast cells promote atherogenesis and induce plaque destabilization in apolipoprotein E-deficient mice. Circulation. 2007; 115(19):2516-2525.

51. Sukhova GK, Shi GP, Simon DI, Chapman HA, Libby
P. Expression of the elastolytic cathepsins S and $\mathrm{K}$ in human atheroma and regulation of their production in smooth muscle cells. J Clin Invest. 1998; 102(3):576-583.

52. Geng YJ, Wu Q, Muszynski M, Hansson GK, Libby P. Apoptosis of vascular smooth muscle cells induced by in vitro stimulation with interferongamma, tumor necrosis factor-alpha, and interleukin-1 beta. Arterioscler Thromb Vasc Biol. 1996; 16(1):19-27.

53. Li JH, Pober JS. The cathepsin B death pathway contributes to TNF plus IFN-gamma-mediated human endothelial injury. J Immunol. 2005; 175(3):1858-1866.

54. Sun J, et al. Critical role of mast cell chymase in mouse abdominal aortic aneurysm formation. Circulation. 2009;120(11):973-982.

55. Zhou X, Hansson GK. Detection of B cells and proinflammatory cytokines in atherosclerotic plaques of hypercholesterolaemic apolipoprotein E knockout mice. Scand J Immunol. 1999;50(1):25-30.

56. Moos MP, et al. The lamina adventitia is the major site of immune cell accumulation in standard chow-fed apolipoprotein E-deficient mice. Arterioscler Thromb Vasc Biol. 2005;25(11):2386-2391.

57. Roselaar SE, Kakkanathu PX, Daugherty A. Lymphocyte populations in atherosclerotic lesions of apoE $^{-/-}$and LDL receptor ${ }^{-/-}$mice. Decreasing density with disease progression. Arterioscler Thromb Vasc Biol. 1996;16(8):1013-1018.

58. Young JL, Libby P, Schönbeck U. Cytokines in the pathogenesis of atherosclerosis. Thromb Haemost. 2002;88(4):554-567. 